La

Révolution

française

\section{La Révolution française}

Cahiers de l'Institut d'histoire de la Révolution française

1 | 2012

L'attentat, objet d'histoire

\title{
Violence politique et transition démocratique : les attentats sous la Révolution française
}

Political violence and democratic transition: political attacks during the French Revolution

\section{Guillaume Mazeau}

\section{OpenEdition}

Journals

Édition électronique

URL : http://journals.openedition.org//rf/380

DOI : $10.4000 /$ Irf.380

ISSN : 2105-2557

Éditeur

IHMC - Institut d'histoire moderne et contemporaine (UMR 8066)

Référence électronique

Guillaume Mazeau, « Violence politique et transition démocratique : les attentats sous la Révolution française », La Révolution française [En ligne], 1 | 2012, mis en ligne le 29 avril 2013, consulté le 30 avril 2019. URL : http://journals.openedition.org/Irf/380 ; DOI : 10.4000/Irf.380

Ce document a été généré automatiquement le 30 avril 2019.

(c) La Révolution française 


\section{Violence politique et transition démocratique : les attentats sous la Révolution française}

Political violence and democratic transition: political attacks during the French Revolution

Guillaume Mazeau

1 À la fin $\mathrm{du} \mathrm{xx}^{\mathrm{e}}$ siècle, beaucoup d'historiens ont renoncé à expliquer la radicalisation politique qui touche la France entre 1789 et 1794 par l'existence d'une «idéologie révolutionnaire », notion dont le caractère artificiel et polémique renvoyait à une période de guerre froide historiographique désormais révolue. Se détournant de la seule analyse des discours et des idées politiques, ils se sont tournés vers les pratiques et les expériences, tout particulièrement vers la violence. De celle-ci, ils ont surtout retenu la dimension collective. Objet privilégié de la réflexion en sciences humaines en raison d'une longue tradition de recherche sur les génocides et massacres de masse des guerres mondiales, réactualisé par les événements de l'ex-Yougoslavie (1991-2001) et du Rwanda $(1994)^{1}$, le massacre est dès lors devenu un objet central de l'historiographie de la fin du $\mathrm{xVIII}^{\mathrm{e}}$ siècle, confortant l'idée selon laquelle cette période se traduit par une aggravation sans précédent des atrocités civiles et militaires. Le plus souvent, révolution et violence sont ainsi de nouveau systématiquement associées. Les travaux qui discutent cette thèse sont pourtant nombreux et ne proviennent pas d'idéologues de la tradition jacobine. Sans nier la brutalité des carnages, ils soulignent combien ce lien ne peut résumer la période ${ }^{2}$. Plutôt que de continuer à réifier «la violence révolutionnaire » comme le produit d'une idéologie spécifique, il semble en effet plus pertinent d'étudier «les violences» de la Révolution dans leur diversité, selon leurs contextes temporels, spatiaux et sociaux, pour mieux comprendre leurs fondements, ainsi que leur rôle dans les événements politiques ${ }^{3}$.

Cette mise en contexte implique de revenir sur les définitions habituellement utilisées pour étudier «la violence». La focalisation sur les actes collectivement perpétrés pour blesser ou tuer les individus révèle ses limites. La période révolutionnaire française est en 
effet marquée par de très nombreux types d'atteintes aux personnes et aux biens qui débordent ce seul phénomène. Souvent minorées, figées comme de simples invariants culturels ou amalgamées à d'autres types de pratiques, ces formes spécifiques de violence, à la fois réelles et symboliques, ne peuvent pourtant être écartées au prétexte qu'elles semblent moins atroces, qu'elles ne visent pas toujours des personnes et que leurs effets sont souvent difficiles à mesurer. C'est la thèse de cet article : un grand nombre de gestes et sans lien apparent entre eux puisent dans le répertoire connu de la rébellion de l'époque moderne voire médiévale et fondent les pratiques de la violence politique des siècles suivants : une violence dont la visée est de plus en plus immatérielle, mais qui est également ressentie comme de plus en plus dévastatrice.

Pendant la Révolution française, beaucoup de violences visent des emblèmes politiques, humains ou non humains. Constamment amalgamés au vandalisme, au pillage délictueux ou à l'assassinat, ces gestes ne se limitent pourtant ni à détruire ni à éliminer, mais expriment un message et provoquent des réactions émotionnelles qui pèsent de plus en plus sur les décisions politiques ou déclenchent l'action directe, participant ainsi à construire l'«opinion publique», artefact aux contours incertains, comme instance centrale de la transition démocratique. Ainsi défini, l'« attentat » se distingue clairement de l'« iconoclasme », du « massacre », mais aussi de l'« assassinat » et de la « vengeance ».

Et pourtant, malgré son omniprésence, l'attentat reste une catégorie invisible de l'action politique révolutionnaire. Au-delà de leur apparence hétéroclite, la prise et la destruction de la Bastille, les incendies des châteaux, l'arasement des maisons des rebelles, des tours, des donjons et des clochers, les décapitations des statues des rois et des saints, les pillages, l'exécution de Louis XVI et les meurtres des porte-parole et héros populaires, méritent d'être étudiés ensemble, parce qu'ils relèvent du même procédé : faire peur et provoquer une réaction non maîtrisée. Tous ces actes, ici réunis dans un corpus hétéroclite, ne réunissent certes pas toujours toutes les conditions pour être entièrement définis comme des attentats politiques. Pourtant, ils revêtent tous au minimum une dimension "attentatoire» qui les distingue d'autres formes de violence. Souvent insaisissable, difficile à délimiter, la catégorie d'«attentat » sera donc plus globalement l'occasion de réfléchir sur les mutations des pratiques de violence politique, et tout particulièrement sur les conditions historiques d'émergence du "terrorisme», qui marque de son empreinte la période contemporaine et qui, pourtant, fait encore l'objet d'interprétations très contradictoires dans les divers champs des sciences humaines ${ }^{4}$.

5 Après avoir montré que les attentats, apparaissant dans un nouveau contexte historique, doivent leur émergence à la rapide et profonde transition politique de la fin $d u \mathrm{xvIII}^{\mathrm{e}}$ siècle, on tentera de distinguer leur spécificité au sein des multiples pratiques de violence de la période, ainsi que leur rôle dans le processus révolutionnaire.

\section{Un nouveau régime de violence}

\section{Un climat attentatoire}

6 À partir des années 1750 grandit un nouveau climat de défiance envers les autorités politiques et sociales. Progressivement, les actes d'opposition et de sédition, des plus modestes aux plus téméraires, changent de nature et de signification. En 1757, après avoir tenté de tuer Louis XV, Robert François Damiens est non seulement accusé d'avoir porté atteinte au corps sacré du roi, mais aussi d'avoir offensé la nation, dont le rôle politique 
ne cesse de s'affirmer ${ }^{5}$. Même s'il échoue, l'assassinat terrorise donc bien plus les contemporains que celui commis en 1610 contre Henri IV, parce qu'il augmente la portée de l'acte sacrilège contre le roi ou la monarchie : paradoxalement, l'essor de l'« opinion publique » et de la nation, encore pensée comme une communauté de sujets fidèle au roi, renforce aussi la force de la royauté dans l'imaginaire collectif ${ }^{6}$. Comme le tremblement de terre survenu en 1755 à Lisbonne, le geste de Damiens est ressenti comme une véritable rupture de l'ordre du monde. Déjà désenchantée, la monarchie ? Loin de là. Les effigies du roi qui quadrillent l'espace public continuent d'être nimbées d'une aura particulière. Dans toute l'Europe, la répétition des attaques contre les corps royaux entraîne une re-sacralisation des monarchies. Après les tentatives d'assassinat contre Louis XV en 1757, Joseph $\mathrm{I}^{\text {er }}$ de Portugal en 1758, puis le tsar Pierre III en 1762, l'Europe entière est obsédée par la mort du roi. Trop associés aux monarchomarques, les jésuites, expulsés de plusieurs royaumes puis supprimés par le pape en 1773, sont les toutes premières victimes de cette peur mondialisée du régicide ${ }^{7}$. L'ampleur inédite de cette onde de choc révèle le rôle croissant du "public » dans la vie politique européenne. Audelà des gens d'esprit, en dehors des alvéoles autorisées de sociabilité dans lesquelles la critique se développe peu à peu, l'« opinion » devient une donnée majeure de la prise de décision politique ${ }^{8}$. En raison de la survivance des représentations organicistes du royaume (la mort du dauphin Louis-Joseph le 4 juin 1789 est un drame national et jusqu'en novembre 1791, l'Assemblée nationale continue de publier les bulletins de santé sur l'« indisposition du roi »), la vie du roi continue d'être liée à celle de ses sujets. Même si elles remettent en cause l'irrévocabilité de ce lien organique, les conceptions contractuelles de l'autorité politique amplifient et déplacent progressivement le choc des attaques contre le roi : alors qu'auparavant, les régicides étaient avant tout interprétés comme des offenses à la sacralité de la royauté, ils sont désormais aussi de plus en plus vécus comme des agressions contre le corps politique de la nation. En même temps que le roi, c'est donc le peuple qui est atteint. L'évolution de la gravité du crime de la lèsemajesté en témoigne : par rapport aux crimes de lèse-majesté divine et humaine, qui ne concernent "que» la sacralité du corps royal, les crimes de lèse-majesté humaine (rébellion, conspiration, trahison, mais aussi faux-monnayage), prennent de plus en plus d'importance aux yeux des réformateurs, car ils nuisent au bien public: selon Beccaria, ces crimes sont les plus graves car ils « détruisent la société ou ceux qui la représentent ${ }^{9}$ . Les théories du tyrannicide s'adaptent à cette nouvelle conception d'une souveraineté pensée comme partagée ou même déléguée par la nation au monarque. La défiance envers le roi ne se justifie plus seulement comme au $\mathrm{XVI}^{\mathrm{e}}$ siècle par la défense de l'orthodoxie religieuse, mais par la rupture du contrat politique, qui entraine une dégénérescence de la monarchie en despotisme : des colonies anglaises d'Amérique du nord à la France, en passant par l'Angleterre, l'Irlande, Genève, les Provinces-Unies et les Pays-Bas autrichiens, une grande partie des révoltes et révolutions de la seconde moitié du XVIII ${ }^{\mathrm{e}}$ siècle éclatent lorsqu'il apparaît que ce contrat n'est plus respecté par le détenteur du pouvoir. Il est désormais possible de penser et d'écrire que l'autorité politique n'est plus intangible, mais qu'elle résulte d'un consentement public fragile et en constante négociation.

7 Le royaume de France n'échappe pas à cette évolution. Malgré le rappel solennel du secret d'État par Louis XV lors de la séance de la Flagellation (1766), le sentiment s'installe que les conflits politiques se jouent désormais sur la place publique. À partir des années 1770, les multiples scandales politiques, sexuels et financiers salissant l'image de la cour 
sont perçus comme des atteintes plus globales à la dignité de la monarchie et même de la nation ${ }^{10}$. Face à cette marée montante, l'appareil administratif et policier, maniant à la fois la contrainte politique (censure préalable, permission tacite, désinformation, répression) et les tractations avec les libellistes étrangers, semble bien impuissant : dans ce contexte de multiplication des affaires politiques, les autorités sont tout aussi incapables de maîtriser la circulation des informations qu'elles le sont lorsque les rumeurs du complot de famine se répandent dans les provinces frappées par la disette ${ }^{11}$.

Insensiblement, un véritable climat attentatoire s'immisce dans la vie politique: publiquement formulé ou intimement rêvé, l'assassinat du roi devient un fantasme partagé de l'imaginaire populaire. L'intrusion de ce tabou dans la sphère publique ne signifie surtout pas que le roi est définitivement désacralisé. Aimer et tuer le roi participent encore de la même culture du sacré monarchique, justifiant, en cas de trahison du monarque, le passage de l'adoration à la haine ${ }^{12}$. C'est précisément pourquoi en 1791, la fuite de Louis XVI puis la révélation de ses tractations avec l'étranger sont ressenties comme des attentats contre la nation. Mais avant même la Révolution, la propagation du fantasme régicide révèle combien l'attentat contre le roi, qu'il soit redouté ou espéré, est désormais identifié comme le mode d'action qui pourrait, plus que les autres, remédier aux crises politiques du royaume.

Courant après l'opinion, les autorités ne parviennent pas à juguler le climat d'opposition qui s'installe puis change de nature. Les mots s'accompagnent de plus en plus d'actes concrets. L'expression publique de la défiance envers les abus de la monarchie, ses emblèmes et, plus largement, l'autorité politique, religieuse et sociale, se traduit non seulement par l'essor des manifestations non violentes, mais aussi par une montée des attaques contre les forces de l'ordre, les emblèmes du pouvoir ou les élites rurales et urbaines, que ce soit en France pendant la Guerre des Farines (1775), en Angleterre, lors des émeutes paysannes et urbaines de la seconde moitié du XVIII siècle, notamment pendant les Gordon Riots (1780) et enfin pendant la guerre d'Indépendance américaine ${ }^{13}$. Lors de ces événements, les émeutiers visent de plus en plus clairement les dépositaires de la force publique (commissaires de police, des douanes), les lieux de l'autorité (dépôts de mendicité, hôpitaux, hôtels des lieutenants de police, maisons des commissaires) ou les objets symbolisant l'injustice (machines de l'industrie textile) ${ }^{14}$.

Défier le pouvoir, même symboliquement, à l'aide de moyens modestes mais utilisés au cœur de l'espace public, fait d'ailleurs partie des stratégies d'opposition des plus humbles, depuis plusieurs siècles: les historiens des révoltes médiévales, des Frondes et des guerres de religion l'ont suffisamment montré ${ }^{15}$. Ces modes d'action symboliques participent de la politisation quotidienne des populations : depuis le $\mathrm{XVI}^{\mathrm{e}}$ siècle, les fêtes et carnavals, accompagnés de leurs rituels d'inversion, de leurs mascarades et de leurs brimades, renversent symboliquement l'ordre du monde, lorsqu'ils ne débouchent pas sur de véritables révoltes ${ }^{16}$. De plus en plus encadrés par les autorités politiques et religieuses qui les considèrent comme préjudiciables à la police des mœurs, ces moments complexes perdent progressivement leur rôle de soupape politique et sociale, mais lèguent à l'action politique des $\mathrm{XVIII}^{\mathrm{e}}$ et $\mathrm{XIX}^{\mathrm{e}}$ siècles un répertoire de mots et de gestes, abondamment recyclé pendant les périodes de crise importante et de révolution: Peter Shaw a montré comment pendant la Révolution américaine, le rituel du goudron et des plumes, infligé par les Insurgents aux commissaires des douanes, vise à violenter mais aussi à humilier ceux-ci en les exhibant au cours d'une parade carnavalesque ${ }^{17}$. 
11 En dehors de ces moments d'exception, il existe d'autres formes d'atteintes aux autorités politiques et religieuses. Sous l'Ancien Régime, il est en effet toujours possible de recourir à une violence médiatisée ou symbolique que permettent les mauvais discours, la littérature et images scandaleuses, mais aussi le blasphème ou l'iconoclasme ${ }^{18}$. Dans ces gestes et paroles, la violence dépasse d'ailleurs déjà son objet immédiat : au-delà de la victime ou de l'objet concerné, elle vise à atteindre la dignité politique ou religieuse dans son ensemble en transgressant la sacralité qui leur est associée. Bien avant les années 1780 , un certain nombre de mécanismes sociaux et culturels permettent donc d'obtenir un effet à la fois emblématique et démultiplicateur à l'action violente.

12 Si les attaques symboliques visent souvent le couple royal, les plus graves et les plus fréquentes concernent les ministres ou les proches du pouvoir. En 1787 et 1788, Loménie de Brienne, Calonne, Lamoignon, mais aussi de la duchesse de Polignac sont tour à tour exécutés symboliquement lors de fêtes carnavalesques ${ }^{19}$. Liées à des pratiques subversives ordinaires et ritualisées (les chahuts, les charivaris), perpétrées par des jeunes étudiants, apprentis et garçons de boutique dans le cadre d'institutions sociales d'Ancien Régime (les bachelleries, reinages et autres associations festives), ces violences ritualisées se politisent de plus en plus dans les années 1780 : à Paris, la procession de l'Homme de la rue aux Ours, pendant laquelle les habitants du quartier Beaubourg pendent et brûlent une effigie d'un Garde Suisse en mémoire de la destruction d'une statue de la Vierge au $\mathrm{XV}^{\mathrm{e}}$ siècle, est supprimée de fait par la police en 1789 , qui craint le risque d'une sédition ${ }^{20}$. Parallèlement, le soutien aux prisonniers de la Bastille (Latude), la sympathie à l'égard de bandits comme Cartouche, Mandrin et de criminels comme Desrues (exécuté en 1777), ou même de criminels de lèse-majesté comme Damiens (1757), révèle la popularité montante de ceux qui contreviennent à l'ordre public, économique ou social imposé par la monarchie ${ }^{21}$. Cette contre-culture d'opposition vise aussi la dignité publique des élites sociales. Si les trois cents manifestations et émeutes de 1788 et 1789 s'apparentent à de classiques troubles de subsistance, les élites politiques et marchandes y sont plus directement mises en cause que lors des mouvements précédents ${ }^{22}$.

\section{Combats pour la souveraineté}

13 En s'attaquant aux emblèmes ou aux représentants du pouvoir, les minorités insurgées de la seconde moitié du XVIII ${ }^{\mathrm{e}}$ siècle cherchent de plus en plus à exprimer leur désaccord et à utiliser leur position de faiblesse en mobilisant une force en pleine expansion, l'opinion publique, au-delà du monde des salons et autres lieux de sociabilité des Lumières. En raison de la liberté d'expression, de l'essor des médias et de la participation croissante de la société civile à la vie politique à partir de 1789 , le peuple, et plus seulement l'opinion éclairée, devient un acteur central des événements, d'autant que les autorités échouent toujours à policer l'expression publique des opinions ${ }^{23}$. Au milieu du siècle, la traque et la punition des mauvais discours étaient spectaculairement mises en scène: en 1758, Moriceau de La Motte, huissier des requêtes de l'Hôtel, avait été exécuté pour avoir tenu des " propos séditieux et attentatoires à l'autorité royale, contre le roi, le parlement, et des personnes en place ». En 1789, la brusque dérégulation politique de la parole publique fragilise les anciennes pratiques de contrôle de l'expression, de censure, de manipulation et de désinformation. La parenthèse sera courte : au début du XIX ${ }^{e}$ siècle, les autorités politiques disposeront de nouveaux outils pour sonder et maîtriser l'opinion publique ${ }^{24}$. Ephémère, cette nouvelle donne transforme néanmoins radicalement les modes d'action 
dans l'espace public. Pour être efficace, un acte doit désormais parvenir à «toucher » un maximum d'individus. Dès lors, le geste en lui-même ne compte pas nécessairement plus que son image et ses effets induits. Commis au cœur d'un espace public de plus en plus ouvert, connecté et médiatisé, dans lequel les actions spectaculaires peuvent susciter une empathie et faire basculer les situations, certains actes trouvent de ce fait des résonances inédites. Ils se traduisent par une amplification de la peur et du sentiment de violence. Ainsi, Micah Alpaugh a montré combien les manifestants de l'année 1789, majoritairement non-violents, tentent néanmoins de faire pression sur les autorités en défilant avec leurs armes, pratiquant une politique de l'intimidation: autant que la violence, c'est la menace et la peur de la violence qui définit la protestation publique pendant la période révolutionnaire ${ }^{25}$. C'est pourquoi à la fin du XVIII ${ }^{\mathrm{e}}$ siècle, l'attentat, principalement destiné à défier le pouvoir et à frapper l'opinion publique, devient un des modes privilégiés de l'action contestataire.

En parallèle, l'évolution de l'usage du mot révèle les combats pour l'exercice de la souveraineté. Le roi ou les ministres sont de plus en plus accusés d'attentats, quand on leur reproche de trahir les constitutions ou de transgresser les usages politiques $d u$ royaume. Après le « coup de majesté » tenté par Maupéou contre les Parlements (1771), le thème des « attentats des ministres » devient un topique de la critique politique. En maijuin 1789, la résistance du roi aux revendications des députés du Tiers est régulièrement qualifiée d'attentat.

La captation populaire de la souveraineté renverse de ce fait la gravité des atteintes au souverain: alors que sous l'Ancien Régime, le crime de lèse-majesté était considéré comme le plus néfaste à la sûreté générale, c'est, à partir de la fin des années 1780 , le crime de lèse-nation qui remplit ce rôle ${ }^{26}$. La notion juridique d'attentat s'en voit transformée : elle désigne de plus en plus une offense commise à l'encontre de la nation. Le roi n'est d'ailleurs plus le seul à être inviolable : à partir du 23 juin 1789, quiconque porte atteinte aux représentants du peuple devient infâme et traître à la nation. L'expression "lèse-nation » se généralise donc pendant l'été 1789 . Sans être encore très définie, elle désigne des crimes qui ne touchent pas les droits des individus mais ceux de la société tout entière. Un siècle avant les attentats anarchistes, le passage de la lèsemajesté à la lèse-nation dégage donc un type spécifique de crime, qui, au-delà de sa cible, porte atteinte à des individus a priori extérieurs au crime perpétré. Or à la même époque, le crime de lèse-nation est associé au terme d'attentat : selon Robespierre, « les crimes de lèse-nation sont des attentats commis directement contre le droit du corps social ${ }^{27}$. Les prévenus d'un crime si exceptionnel doivent alors être déférés devant un tribunal tout aussi extraordinaire: la Haute Cour nationale, chargée de «venger, par des formes paisibles, les attentats contre la Constitution $»^{28}$. Sans être explicitement nommée, la lèsenation est finalement codifiée en 1791 sous la rubrique « crimes et attentats contre la chose publique » (Deuxième partie, titre I) ${ }^{29}$.

Inséparables de la naissance de sociétés fondées sur l'importance croissante de l'opinion publique populaire, les attentats de la fin du XVIII ${ }^{e}$ siècle se voient donc placés au centre des combats pour la souveraineté dans un contexte de rapide transition politique. Dans leur genèse, ils sont donc intimement liés au phénomène révolutionnaire et se retrouvent d'ailleurs au centre des débats sur l'inflexion que la révolution fait prendre à l'histoire, vers le déclin ou le progrès, la civilisation ou la barbarie. 


\section{Une gradation dans l'horreur?}

17 Les attentats anarchistes de la fin du xixe siècle marquent une rupture indéniable dans l'histoire de la violence politique : réalisés avec des explosifs, ils tuent à l'aveugle un grand nombre de victimes considérées comme innocentes. Ils sont donc souvent considérés comme les matrices du terrorisme contemporain ${ }^{30}$. L'étude des attentats de la fin $d u$ XVIII $^{\mathrm{e}}$ siècle conduit pourtant, à la suite du travail de Karine Salomé sur le XIX siècle, à relativiser cette évidence ${ }^{31}$.

L'impression selon laquelle les assassinats politiques de la période révolutionnaire s'inscriraient dans l'histoire «classique » des meurtres politiques, est en grande partie erronée $^{32}$. En premier lieu parce que la fin du XVIII ${ }^{e}$ siècle se caractérise par l'utilisation d'armes de destruction de plus en plus massive. Deux siècles après la conspiration des poudres (1605) et quelques années avant la fameuse « machine infernale » de la rue SaintNicaise (1800), un certain nombre d'actes violents sont réalisés à l'aide d'explosifs et donnent le sentiment d'une aggravation de l'horreur. Tout commence dès l'été 1789, en Haute-Saône, avec l'immense malentendu de l'explosion du château de Quincey. Le 19 juillet, alors que des soldats et paysans sont reçus par le seigneur du lieu pour fêter le récent rappel de Necker, une partie du château explose, entraînant plusieurs morts. L'épisode est aussitôt dramatisé à l'Assemblée par un député de Franche-Comté33. Prenant une importance totalement démesurée, l'accident est interprété comme un attentat: le seigneur des lieux, M. de Memai, conseiller au Parlement de Besançon, aurait attiré le Tiers-Etat dans un guet-apens. Exagérément médiatisée, l'affaire de Quincey devient pourtant un traumatisme fondateur et prend donc place dans l'histoire des attentats politiques, qui tirent au moins autant leur importance de l'imaginaire que des pratiques. Beaucoup sont désormais persuadés que les aristocrates sont prêts à utiliser les violences de guerre pour tuer des civils innocents. Les corps démembrés des victimes de Quincey sont méthodiquement décrits, suscitant l'indignation: la bombe n'a laissé que "des hommes flottant dans leur sang, des cadavres épars, et des membres palpitants ", ou " des cadavres amoncelés, des membres épars, des débris d'édifices ébranlés ou abattus par la commotion $^{34} »$. Qualifié d'acte de barbarie contre le droit des gens, l'attentat imaginaire de Quincey (M. de Mémai sera innocenté en 1791) terrorise les populations et amplifie l'embrasement des campagnes franc-comtoises ${ }^{35}$. La propagation de la nouvelle de l'«attentat » provoque des soulèvements, des pillages et une vague d'émigration vers la Savoie ${ }^{36}$. L'événement resté dans l'histoire sous le nom d'« attentat de Quincey », crée un précédent : dès lors, la terreur des attentats à l'explosif, considérés comme une marque de la nouvelle barbarie nobiliaire, devient obsédante. Quinze jours plus tard, la rumeur selon laquelle la salle des États-Généraux a été minée par le roi justifie que l'on perquisitionne, dans la nuit du 2 au 3 août, les souterrains des écuries du comte d'Artois, d'où les boyaux sont censés partir ${ }^{37}$. La dramatisation qui s'exprime lors de la nuit du 4 août est en partie liée à ce contexte de peur d'une destruction totale du Tiers Etat. La peur des attentats devient obsédante. Le 7 août, la découverte de chiffons imprégnés de soufre entre deux bornes dans la rue Saint-Bon, provoque la panique ${ }^{38}$. En octobre, c'est le Palais-Royal et l'Hôtel de Ville que les conspirateurs s'apprêteraient à faire sauter ${ }^{39}$. Le 13 décembre, l'« attentat Billon » relance l'impression que les ennemis de la Révolution sont désormais prêts à utiliser des techniques de destruction massive contre la nation. $\mathrm{Ce}$ jour-là, furieux d'avoir été exclu du corps des arquebusiers de la garde nationale de Senlis, Louis Michel Rieul Billon tire sur la compagnie au moment où elle passe devant 
chez lui et fait sauter sa maison, laissant des dizaines de morts et blessés. Après avoir détruit plusieurs maisons, la déflagration est entendue jusqu'à Chantilly ${ }^{40}$. Tandis que la dépouille du forcené est portée aux fourches patibulaires, la rumeur d'un complot se répand partout. Senlis est bientôt décrite comme une ville de contre-révolutionnaires. Cette dramatisation s'explique par la mort de nombreux innocents: en piégeant sa maison, Billon a manifestement voulu tuer au hasard. Cette violence aveugle est vécue comme un traumatisme par les survivants et explique leur exceptionnelle prise en charge par les autorités politiques. Alors que la municipalité de Senlis, le chapitre de la cathédrale et les particuliers fournissent les premiers subsides aux familles touchées, une demande de secours est officiellement faite au Premier ministre des finances, Necker. Afin d'estimer les besoins, le comité permanent de la ville recense le nombre exact des victimes et de leurs familles. Il en publie la liste avec les noms et professions, afin d'assurer une répartition équitable des secours et de provoquer la sollicitude du public à l'égard des victimes, auxquelles le comité rend hommage en assistant à tous leurs enterrements. Qu'ils soient élus, gardes nationaux ou simples citoyens, ceux qui ont perdu la vie pour avoir tenté d'arrêter le forcené, sont célébrés comme des héros ${ }^{41}$. La volonté d'un anonyme de passer rapidement à la postérité, la violence de l'attentat, conduisant à un premier moment d'hébétude et d'incompréhension (« on n'entendait que des hurlements confus »), le mode opératoire (le guet apens, le recours à l'explosif), l'épouvante et l'indignation des survivants, l'identité des victimes (la plupart ne sont pas impliquées dans l'événement qui a conduit Billon à se venger) et la réaction des autorités politiques (le secours public aux victimes de l'attentat), font de l'explosion de Senlis un marqueur dans l'histoire des attentats politiques. On y retrouve en effet tous les mécanismes qui distingueront les événements analysés par Karine Salomé pour le XIX ${ }^{e}$ siècle ${ }^{42}$.

19 Après l'attentat de Billon, l'attentat à la bombe, tuant de manière très violente et indéterminée, devient un repoussoir de la société civique idéale, régénérée et civilisée par la révolution. L'auteur d'attentat devient un archétype de l'ennemi public. Peu de jours après l'événement de Senlis, Antoine-François Momoro accuse le chapelain de SainteMarie L'Egyptienne de vouloir faire sauter le corps de garde du bataillon de Saint-Leu, et de vouloir imiter Billon ${ }^{43}$. Tous les symboles de la révolution deviennent des cibles potentielles et la peur se répand, rythmant le temps révolutionnaire de sa pulsation si particulière. Au début de 1790, le bruit circule que la maison de La Fayette a été minée. En juillet, tous les remblais de terre, souterrains et caves qui avoisinent le Champ de Mars sont bouchés et surveillés afin d'éviter un grand attentat qui viserait «à faire sauter et vouer à la mort toute l'élite de la France ». L'égout servant à la décharge des eaux de l'École militaire, qui passe sous le lieu de la fête, est inspecté puis préventivement inondé ${ }^{44}$. En septembre 1791, on raconte sur les marchés que les boulangeries qui augmenteraient le prix du pain seraient bientôt visées ${ }^{45}$. Trois mois plus tard, à Toul, les révolutionnaires se félicitent d'avoir démantelé une "conspiration des poudres", qui visait à détruire le magasin à poudre et l'hôtel de la commune ${ }^{46}$. À Paris, à la même époque, un ouvrier des carrières de Paris est accusé de vouloir faire exploser plusieurs hôtels du faubourg Saint-Germain ${ }^{47}$. Le 29 janvier 1792, Jean-Louis Carra, rédacteur des Annales Patriotiques et Littéraires, assure avoir vu une lettre attestant "qu'on minait, pendant la nuit, le terrain sous la salle de l'Assemblée nationale pour la faire sauter $\aleph^{48}$. Fin juin 1792, l'horloger Frossard, qui tient boutique à la Bastille, affirme à la police que des conspirateurs s'apprêtent à faire exploser le magasin à poudre, au moyen d'un souterrain $^{49}$. En 1794, les explosions de la poudrerie de Grenelle et de l'arsenal de Landau 
sont aussitôt interprétés comme des attentats ${ }^{50}$. Pendant la Révolution, l'attentat à l'explosif devient donc un fantasme permanent.

Ces multiples précédents relativisent d'autant la nouveauté de l'attentat de la rue SaintNicaise (3 nivôse an 9/24 décembre 1800). Plus d'un mois auparavant, un projet d'attentat à la machine à feu, préparé contre le Premier consul, avait d'ailleurs été démasqué51. Souvent pensé isolément, l'événement doit aussi être relu dans le contexte plus large d'un terrorisme chouan mené dans l'Ouest entre 1800 et 1804 contre la pacification imposée par Bonaparte, se traduisant par une multitude d'attaques échappant au combat réglé. Ces actes de "chouannerie à volonté » sont régulièrement qualifiés d'attentats par leurs contemporains, qui les accusent de « saper l'ordre » et de déstabiliser l'opinion publique ${ }^{52}$ . Dans les campagnes occidentales et méridionales, marquées par la chouannerie, le brigandage et la "Terreur Blanche", les pratiques de la "petite guerre» ou guérilla précèdent le mot, apparu lors de l'invasion de l'Espagne par les troupes napoléoniennes $(1807-1812)^{53}$. Le « terrorisme » et la guérilla ne peuvent être confondus, mais ils sont tous deux utilisés à la même époque et résultent d'une confusion croissante entre violences de guerre et de paix ${ }^{54}$. Cette porosité vient en partie des moyens techniques employés. Beaucoup d'attentats sont commis à l'explosif grâce à la diffusion massive d'ouvrages de vulgarisation de la pyrotechnie depuis les années 1750 , permettant une démocratisation de la fabrication de bombes artisanales et une prolifération des techniques dont la maitrise était jusqu'ici restée monopolisée par la corporation des artificiers ${ }^{55}$. Ces derniers sont de ce fait de plus en plus suspectés de mettre leurs compétences au service de la contre-révolution. Au début du mois d'août 1789, aux Enfants-Trouvés, la police arrête une voiture chargée de poteries et de faïences, mais aussi de petits plombs, de fusées et de pétards, et refuse de la rendre à son propriétaire, le suspectant de préparer un attentat ${ }^{56}$. Les ateliers clandestins de fabrication de poudre sont traqués et, lorsqu'ils sont mis à jour, démantelés ${ }^{57}$. Même lorsqu'ils ne sont pas préparés à l'aide d'armes nouvelles, nombre d'attentats sont intentionnellement commis comme des actes de guerre : en 1793, Charlotte Corday arrive à Paris pour tuer Marat en se présentant comme l'avant-garde de l'armée fédéraliste. Elle pense qu'en semant la panique, la mort de l'Ami du peuple facilitera l'arrivée des troupes parties de Caen et démobilisera les sans-culottes parisiens.

Ces éléments permettent de mieux comprendre les origines de la violence terroriste contemporaine, dont le moment anarchiste n'est qu'une étape parmi d'autres. Depuis la fin $\mathrm{du} \mathrm{xvII}^{\mathrm{e}}$ siècle, dans le cadre de la guerre de siège maritime, les monarchies européennes recourent, grâce à la pyrotechnie, à des bombes ou " machines infernales ", constituées de vaisseaux chargés de barils remplis de poudre, de boulets rouges et de matériaux métalliques, entraînant, en temps de guerre, l'élimination à l'aveugle de nombreux civils. En 1784, dans les Annales Patriotiques et Littéraires, le journaliste Linguet signale l'emploi de ces «batteries flottantes » lors du siège de Gibraltar, tenu contre les Anglais, et destinées à " produire la plus épouvantable explosion qui ait jamais déchiré l'atmosphère $»^{58}$. Après 1789 , la Révolution est accusée d'entraîner une dérégulation et une dissémination des armes de destruction totale auparavant monopolisées par l'État. De simples individus ou de petits groupes trop faibles pour atteindre une grande visibilité peuvent désormais provoquer des carnages et répandre la terreur en s'appropriant, en temps de paix, les techniques particulièrement violentes de plus en plus utilisées depuis la Guerre de Sept Ans (1756-1763) 
22 À la fin du xviII ${ }^{e}$ siècle, les attentats sont donc perçus comme une nouvelle forme de violence, particulièrement horrible et condamnable. Leurs auteurs suscitent bien plus d'indignation et d'effroi que les criminels «ordinaires». Ils sont décrits comme des monstres qui, transposant la guerre dans la paix, ont transgressé les normes habituelles d'exercice de la violence. L'attaque par surprise, le caractère spectaculaire de ces actes commis pour semer la peur et le choix de cibles très populaires ou totalement inconnues, donnent l'impression que certains individus sont désormais prêts à s'affranchir des codes de l'honneur et de la civilité qui régissent les normes sociales des Lumières, pour détruire l'ordre public et social. N'importe qui peut être visé, n'importe quand et n'importe où. Ainsi considérés, les attentats peuvent être rangés dans la catégorie des nombreux indices d'une brutalisation de la violence, due au contexte de guerre et de terreur, mais aussi à l'ensauvagement et l'animalisation de l'ennemi, rangé dans une infra-humanité : l'auteur d'attentat n'est pas un criminel ordinaire, ni un simple fanatique, c'est un monstre.

Pourtant, les attentats répondent également à une volonté de «rentabiliser » et d'économiser la violence. En touchant des individus, des signes et objets emblématiques, les attentats visent généralement plus à terroriser ceux qui survivent qu'à faire souffrir leurs victimes, même si certains d'entre eux peuvent s'accompagner de rituels imitant les supplices publics. Lorsque Charlotte Corday affirme avoir «[...] tué un homme pour en sauver cent mille", elle révèle la dimension dissuasive, préventive et utilitariste de l'attentat qu'elle vient de commettre ${ }^{60}$. Même s'ils sont unanimement condamnés, ces gestes de violence correspondent donc également au nouveau contexte de refus d'une violence arbitraire, injustifiée et débridée, qui imprègne les écrits des réformateurs et la sensibilité sociale de la fin du XviII ${ }^{\mathrm{e}}$ siècle. La sensibilité à l'égard de la violence change dans les pratiques: si les attentats à la bombe pulvérisent les corps, ils permettent également à leurs auteurs de ne pas donner directement la mort.

Les attentats de la fin du XVIII ${ }^{\mathrm{e}}$ siècle se caractérisent donc à la fois par une mise à distance de la violence et par un sentiment d'augmentation de la barbarie. Civilisation et brutalisation ne peuvent être systématiquement opposées: leur coexistence, qui constitue une des pierres d'achoppement des analyses de la Terreur, est due aux contradictions liées aux transitions politiques que sont les révolutions. Cette concomitance signale l'entrée dans une modernité de la violence politique qui caractérisera les deux siècles suivants.

Saisis dans les pratiques, les attentats de la période révolutionnaire se caractérisent par une transformation des violences antérieures. Se traduisant par des attaques à la fois réelles et symboliques contre des emblèmes matériels et humains, ils jouent un rôle évident dans la radicalisation des événements et justifient l'emploi d'une politique de répression terroriste.

\section{Pratiques de l'attentat}

\section{Attentats matériels}

Bien avant la fin du XVIII ${ }^{e}$ siècle et particulièrement dans les périodes de guerre civile, les emblèmes jouent un rôle central dans l'actualité politique : par exemple, Denise Turrel a montré que pendant les guerres de Religion, l'écharpe blanche devient un marqueur politique qui mobilise les protestants au cœur des affrontements les plus violents, en 
opposition à la croix catholique, avant d'être institutionnalisée par Henri IV au sein du nouveau système de représentation de la monarchie ${ }^{61}$. Mais ce rôle politique des emblèmes matériels est encore plus évident à la fin du XVIII ${ }^{\mathrm{e}}$ siècle, qui voit naître une "société des apparences ${ }^{62}$. L'essor de la culture urbaine, en partie fondée sur les rapports marchands, les pratiques de consommation et la communication visuelle, ajoutée aux progrès de la sécularisation et à la diffusion des doctrines sensualistes, assignent aux objets et aux signes un nouveau rôle dans les usages de l'espace public ${ }^{63}$. Qu'ils soient monarchiques, féodaux, religieux, nobiliaires, patriotes ou républicains, les emblèmes et images envahissent la vie quotidienne des individus ordinaires et tissent un réseau de signes qui transforment les anciennes formes d'action politique (l'iconoclasme, associé à la sacralité des images) et en font apparaitre de nouvelles (les boycotts, les dégradations et destructions, plutôt destinés à mobiliser l'opinion) ${ }^{64}$. Sous la Révolution française, les emblèmes ne sont pas des éléments passifs du décor urbain ou rural. Ils imprègnent les habitus sociaux et façonnent les identités collectives, pour lesquelles on peut engager sa vie $\mathrm{e}^{65}$. Leur simple présence peut déclencher des émeutes ou provoquer la fraternisation. Premiers signes quotidiens du transfert de souveraineté et des combats pour la légitimité, les signes et images deviennent de nouveaux enjeux des luttes politiques ${ }^{66}$. Effectués dans l'espace public, les nombreux effacements, grattages, déchirures, détournements, brisures ou destructions s'apparentent à ce qu'Emmanuel Fureix appelle un "sémioclasme", que l'on ne peut réduire au vandalisme ni même à l'iconoclasme lié à la déchristianisation ${ }^{67}$. Souvent, ces actes accompagnent ou précèdent la violence verbale ou physique: les tout premiers gestes révolutionnaires attaquent l'univers visuel sur lequel les autorités politiques et sociales fondent leur pouvoir quotidien. En retour, ils entraînent la destruction des signes associés aux insurgés, fréquent prélude à une gradation vers la violence. Les attentats matériels ponctuent les premiers actes de sécession lors de la guerre d'Indépendance des États-Unis. En 1774, lors de l'ouverture de la session du Congrès, les Insurgents détruisent une couronne ; en 1776, ils s'attaquent au symbole de la domination de la métropole anglaise dans l'espace urbain : la statue de George III à New York est brisée à son tour. Ces attaques sont aussitôt ressenties comme des actes sacrilèges. Ils galvanisent les patriotes et effraient les Anglais et loyalistes. L'attentat politique révèle ainsi sa double fonction : mobiliser et terroriser.

En France, l'été 1789 commence par une série d'intimidations matérielles, qui font partie de la tradition séditieuse. En mai 1788, à Bordeaux, les vitres de ceux qui n'illuminent pas en l'honneur du rétablissement du Parlement, sont méthodiquement brisées : vingt ans auparavant, de l'autre côté de la Manche, les partisans de John Wilkes avaient fait la même chose contre ceux qui refusaient d'illuminer en l'honneur de son élection ${ }^{68}$. Le 20 juillet à Strasbourg, c'est au tour de celles des magistrats impopulaires. Peu à peu, les violences symboliques à l'encontre des emblèmes ennemis se multiplient. Les attentats matériels émaillent les trois journées des 12,13 et 14 juillet 1789 à Paris, qui font basculer les événements. Le matin du 12 juillet 1789, choqués par l'annonce du renvoi de Necker, 5000 à 6000 manifestants défilent derrière les effigies du ministre congédié et de celui du duc d'Orléans, chargées d'enjeux, car associées à la souveraineté populaire : quatre jours auparavant, une femme avait été fessée en public après avoir craché sur le portrait de Necker. Arrivés place Vendôme, les manifestants, dont certains arborent des cocardes vertes, premiers emblèmes politiques de la Révolution, sont chargés par les cavaliers du Royal-Allemand. Le colporteur François Pépin, qui portait le buste du duc d'Orléans, est tué. Il devient l'une des premières victimes emblématiques de la Révolution ${ }^{69}$. 
L'événement est aussitôt qualifié d'« attentat à la liberté nationale et à la vie de plusieurs citoyens " par le journaliste Loustalot ${ }^{70}$. Ainsi, dès la première journée révolutionnaire, les emblèmes matériels sont au cœur des combats politiques.

Pendant la nuit du 12 au 13 juillet, les deux tiers des barrières de Paris, lieux du prélèvement des octrois et aides, s'embrasent. Ces gestes constituent une des formes connues de la protestation populaire dans les grandes villes : en juin, à Lyon, les barrières des Aides avaient déjà été incendiées ${ }^{71}$. Accompagnant le pillage des bureaux, le déchirement des registres et l'intimidation des commis, ils témoignent d'objectifs bien concrets : supprimer un prélèvement devenu insupportable. Mais ces feux ne se limitent pas à une volonté de destruction: ils sont également destinés à peser sur les débats des États-Généraux. Visant spectaculairement les emblèmes des injustices fiscales, ils prennent une valeur d'avertissement. D'autres formes d'attaques matérielles remplissent cette fonction. Au même moment, à Rouen, un métier automatique est en effet saccagé et ses débris brûlés en plein centre de la ville. La violence contre les «mécaniques » n'est certes pas nouvelle en cet été 1789. Mais les événements donnent une résonance inédite à ces bûchers expiatoires allumés dans l'espace public, au plus fort de la crise politique. Ces feux s'attaquent aux emblèmes du machinisme. Ils attisent la peur patronale des désordres ouvriers et parviennent provisoirement à dissuader la mécanisation des filatures ${ }^{72}$. Cette forme d'activisme associant intimidation, dissuasion et mobilisation de l'opinion publique tranche avec les techniques employées lors des émeutes frumentaires du XVIII e siècle, décrites par Eric J. Hobsbawn (la «négociation collective par l'émeute ») et Edgar P. Thompson (l'« économie morale ») ${ }^{73}$. Le sabotage industriel terrorise les patrons et mobilise l'opinion: deux caractéristiques du mode de l'attentat. Au printemps, la contestation ouvrière des abus patronaux avait pris des formes semblables, lors de la destruction des entrepôts de Réveillon, dans le faubourg Saint-Antoine. Les émeutiers ne pillent alors pas au hasard, mais s'acharnent sur les appartements les plus précieux de Réveillon, qui, prônant une baisse du salaire ouvrier en pleine inflation des prix du pain, avait fini par devenir l'incarnation des affameurs. En avril 1790, alors que les émeutiers assassinent Chatel, le lieutenant de maire de Saint-Denis, ils brisent et saccagent les meubles et biens de son gendre, qui gérait le domaine des dames de Saint-Cyr pour cette ville $^{74}$. Huit ans auparavant, à Londres, lors des Gordon Riots, les émeutiers protestants avaient déjà concentré leurs attaques sur les maisons des riches, accusés de financer la construction de nouvelles églises et écoles catholiques ${ }^{75}$. Même au cœur des émeutes les plus violentes, l'acharnement n'est pas aveugle : il porte sur les emblèmes matériels des autorités politiques et sociales, accusées de comploter contre le peuple.

Ne peut-on relire la « Grande Peur » sous cet angle ? Pendant le printemps et l'été 1789, la rumeur de l'invasion du territoire par des « brigands » se propage dans une grande partie du royaume et suscite une réaction de terreur en chaîne bien connue ${ }^{76}$. La "Grande Peur » est restée dans les mémoires comme le parangon de la violence archaïque des foules paysannes, saccageant les châteaux des seigneurs provinciaux. Au xix siècle, l'image qui revient le plus souvent est celle d'un incendie généralisé, intégrant la Grande Peur dans la légende des séditions paysannes, censées révéler la «nature » violente du peuple ${ }^{77}$. Timothy Tackett a montré combien ces violences sont pourtant extrêmement ciblées : ni destinées à la noblesse ni au système féodal en général, elles visent les mauvais seigneurs locaux. La Grande Peur n'est pas une révolte antifiscale et frumentaire de plus. Les révoltés de 89 vivent dans un autre monde que celui des Jacques (1358), des Nu-Pieds (1639), des Croquants (1624-1643) ou des Bonnets Rouges (1675). Le monde rural de la fin 
du XVIII ${ }^{e}$ siècle est bien plus politisé, ouvert et connecté. Si elles débutent par les pillages des stocks de blé, les insurrections se traduisent surtout par la «visite» des châteaux, l'organisation de banquets charivaresques, mais aussi la dégradation ou la destruction des emblèmes matériels et lieux de mémoire des injustices seigneuriales (châteaux, abbayes, colombiers, bancs, girouettes, terriers), judiciaires (greffes des tribunaux) ou fiscales (maisons des fermes). Les vrais actes de brigandage restent rares ${ }^{78}$. Lorsqu'elles existent, la plupart des violences ne sont pas commises contre des individus, mais contre leurs demeures et leurs biens. Habituellement utilisé lors des réjouissances populaires, le feu soude les révoltés et terrorise les mauvais seigneurs: allumé dans une ambiance carnavalesque, l'incendie est visible à plusieurs lieues à la ronde. La fumée qui s'en échappe signale à tous les environs la dimension à la fois festive et attentatoire de l'événement. Dans bien des cas, ces gestes surviennent après qu'un malentendu a laissé croire à un attentat contre le Tiers État, « la nation » ou « le peuple » : près de Dinan, les émeutiers mettent le feu au château de $\mathrm{M}$. de la Ville-Huchet après qu'un garde national $\mathrm{y}$ a été abattu. Si la Révolution n'invente pas ces feux, elle transforme leur signification : les autodafés et feux de joie deviennent des feux d'intimidation.

Le 14 juillet, les attaques des Invalides mais surtout de la Bastille sont à la fois commises et ressenties comme des actes d'auto-défense du peuple, mais aussi comme des offenses sacrilèges contre l'ordre monarchique et comme des signaux, des avertissements destinés à effrayer les autorités monarchiques, accusées de ne pas accepter la tournure prise par les États Généraux ${ }^{79}$. La prise de la prison d'État s'impose parmi tous les autres comme l'attentat par excellence. Depuis plusieurs décennies, la bâtisse s'élevant au-dessus du faubourg Saint-Antoine était devenue une forteresse «à prendre $»^{80}$. Son attaque, vécue comme un siège et sa destruction spontanée épouvantent littéralement les partisans du roi, qui les qualifient d'«attentats ». Mais en juillet 1789, la radicalisation politique fait glisser la signification du mot : toujours associé à une usurpation de droit, l'« attentat » désigne aussi de plus en plus, sous l'effet des événements, un nouveau mode d'action action violente visant à faire basculer une situation politique en frappant l'opinion publique. Du côté des patriotes, l'attaque puis la destruction de la forteresse vide, médiatisées dans les semaines qui suivent, sont vécues comme des événements magiques faisant advenir la liberté grâce à un coup de force symbolique aussitôt mythifié, trouvant un large écho dans l'opinion nationale et même internationale ${ }^{81}$. En province comme à l'étranger, l'attaque des «bastilles locales» devient le mot d'ordre des patriotes. Les donjons de Vincennes (février 1791) et de Caen (août 1793), en font notamment les frais. Pour la postérité, la légende est en tout cas déjà écrite: l'histoire contemporaine commence avec un spectaculaire attentat politique.

31 La multiplication des emblèmes politiques dans l'espace public augmente d'autant la fréquence et la signification des violences à leur égard. Le $1^{\mathrm{er}}$ octobre 1789 , l'une d'entre elles provoque la plus importante journée révolutionnaire après la prise de la Bastille. A l'opéra du château de Versailles, lors d'un banquet offert par les gardes du corps du roi aux officiers du régiment de Flandre, une cocarde tricolore est piétinée ${ }^{82}$. Vite rapporté par la presse, l'incident fait scandale, favorisant le déclenchement de la marche des femmes à Versailles ( 5 octobre). L'affaire de la cocarde devient le symbole de la nation outragée. Pratique héritée des révolutions antérieures, le port de la cocarde n'est alors qu'un acte volontaire de patriotisme, mais il fait rapidement l'objet d'attaques de la part des contre-révolutionnaires. De plus en plus ressenti comme une injure à la nation, le geste entraîne des rixes sur les marchés entre femmes patriotes et poissardes ${ }^{83}$. 
Paradoxalement, les agressions contre les cocardes renforcent leur importance : parce qu'elles constituent de véritables menaces pour l'ordre public, elles deviennent obligatoires pour les hommes le 8 juillet 1792 et pour les femmes le 21 septembre $1793^{84}$. Dans les territoires conquis, l'arrachage de la cocarde devient une des formes les plus fréquentes de la résistance aux occupants ${ }^{85}$. Progressivement, l'attentat à la cocarde est donc criminalisé. Ceux qui lui portent atteinte sont qualifiés d'« ennemis de la liberté » par la commission militaire du 4 prairial-7 prairial an III (23 mai-27 mai 1795). En l'an VII, les profanations de la cocarde font partie des actes les plus « impies", d'autant que celleci est plus que jamais considérée comme symbole de la prééminence française parmi les nations d'Europe ${ }^{86}$.

Parallèlement, les «mais » ou arbres de la liberté, font l'objet de semblables attaques. Éléments de la culture paysanne, ces mâts ou poteaux droits sont devenus des emblèmes politiques pendant la Révolution américaine (poles ou liberty trees) puis la Révolution batave (orangers contre arbres de la liberté des patriotes) ${ }^{87}$. Parce qu'ils sont de plus en plus identifiés à la révolution, les arbres français, décorés de rubans, de cribles, de cocardes, d'images et d'instruments de travail, deviennent également les cibles d'attentats contre-révolutionnaires. Solennellement plantés dans les bourgs sur places publiques après la destruction des girouettes, des bornes seigneuriales, des fourches patibulaires, des fleurs de lys, des armoiries et des bancs d'église, ils sont attaqués en Bretagne dès l'automne 1792 et parfois remplacés par des croix $^{88}$. Le marquage de l'espace public républicain est perçu comme une agression, un attentat menaçant tellement l'univers visuel de l'Ancien Régime, lié à l'Église et à la monarchie, qu'il provoque la violence et inspire une surenchère opposée. Dans certaines régions, les résistances à la révolution s'expriment par des sonneries de cloches répétées et intempestives, ressenties comme de véritables attentats sonores ${ }^{89}$.

Dans le même temps, les patriotes s'attaquent aux bornes seigneuriales, aux fourches et marques publiques mais aussi aux armoiries et signes distinctifs privés de l'Ancien Régime. Toutefois, les arbres de la liberté, ainsi que les bonnets et cocardes qui les ornent, restent des cibles privilégiées. Les mutilations, abattages ou bûchers accompagnent l'insurrection de l'Ouest après la levée de 300000 hommes en mars 1793. Pour combattre ces attentats, il arrive que les patriotes renforcent la sécurité autour des arbres, surtout pendant les plus fortes crises de l'insurrection (la virée de Galerne en 1793 puis la guérilla chouanne en 1799) ${ }^{90}$. Lorsqu'ils sont commis dans des contextes de fortes tensions, les attentats contre les arbres de la liberté peuvent déclencher une violente répression antiterroriste. En mai 1794, dans le village de Bédoin (Vaucluse), l'arbre de la liberté est arraché. Le bonnet qui le surmontait est jeté dans un puits. Quant à l'affiche qui présentait les décrets de la Convention nationale, elle est lacérée et piétinée. Commis dans un contexte de très fortes tensions régionales, l'attentat provoque une répression exceptionnelle. Plus de soixante habitants sont condamnés à mort, les habitants sont déportés dans les villages voisins, leurs maisons sont incendiées, les champs sont stérilisés au sel, le village est rayé de la carte et l'église est en partie détruite à l'explosif. Comme pour les cocardes, l'essor des conflits autour de ces emblèmes nationaux inspire une législation coercitive. Si les premières mesures répressives apparaissent contre les mutilateurs dès 1793 , c'est la loi du 24 nivôse an VI qui criminalise la dégradation des arbres de la liberté, qualifiée d'attentat (Moniteur Universel, 4 mars 1796) et passible de plusieurs années de détention. Entretemps, la loi du 3 pluviôse an II (22 janvier 1794) a rendu obligatoire la présence d'un arbre de la liberté dans chaque commune du territoire, 
démultipliant la probabilité des attaques. Le 12 janvier 1793, neuf jours avant l'exécution de Louis XVI, des royalistes rouennais qui réclament la libération du roi, scient un arbre de la liberté pour se faire entendre. Mutiler un arbre de la liberté devient un acte de résistance : cette pratique est couramment utilisée contre l'occupant en Belgique, en Suisse, en Italie et par les Barbets du pays Niçois ${ }^{91}$. Investies d'une nouvelle importance, les affiches politiques revêtent également un nouvel enjeu des combats pour la souveraineté : les lacérer, les biffer ou les arracher est souvent perpétré, ressenti et qualifié comme un attentat qui, au-delà de l'objet, vise le nouveau régime. Les statues de la liberté font également l'objet de destructions. Parce qu'elle choque les révolutionnaires et menace souvent l'ordre public, cette pratique est de plus en plus criminalisée : le 3 mai 1790, l'assemblée du district des Enfants-Trouvés déclare ennemis de la nation ceux qui portent atteinte aux décrets de l'Assemblée ${ }^{92}$.

Après la Fête de la Fédération (14 juillet 1790), célébrée dans la foulée de la Constitution Civile du Clergé, les autels de la patrie deviennent les nouvelles cibles privilégiées des attentats contre-révolutionnaires. Considérés comme des monuments garantissant non seulement le serment civique, mais aussi la nouvelle relation entre l'Église et l'État, ils deviennent des enjeux importants des luttes politiques. Les profaner revient à contester symboliquement la stabilité du nouvel édifice politique et moral sur lequel repose la monarchie constitutionnelle. Peu après la Fête de la Fédération, l'autel du Champ de Mars, lieu de mémoire du nouveau pacte national, est saccagé. La sentinelle est attaquée, son uniforme mis en lambeaux. Les radicaux ressentent l'événement comme une profanation ${ }^{93}$. Dans l'Ouest, ces attaques contre les autels de la patrie se multiplient dans les mois qui suivent ${ }^{94}$.

La grande vague d'iconoclasme peut être en partie lue à travers cette histoire des attentats révolutionnaires. Si les enlèvements et destructions des emblèmes de la féodalité commencent dès 1790, l'été 1792 constitue un tournant dans le remplacement des systèmes de représentation politique : dès avant le mois d'août apparaissent les premiers débats sur la destruction des statues des rois de France ${ }^{95}$. Ce type d'iconoclasme rappelle les mutilations des statues de George III en Amérique du Nord pendant les années 1770. Un siècle auparavant, la République anglaise avait elle aussi tenté d'éradiquer les symboles du pouvoir royal, mais après que Charles $1^{\mathrm{er}}$ eut été décapité. En France, les gestes iconoclastes précèdent la chute de la monarchie (dès le mois de mars 1792, les tableaux des Grands sont lacérés, ainsi que les portraits de Louis XV et de la reine). Ils sont donc ressentis par les contre-révolutionnaires comme une effrayante atteinte à la personne sacrée du roi et à la dignité monarchique.

Le décret du 11 août 1792 légalise pour la première fois ce qui, auparavant, était encore considéré comme un attentat de lèse-majesté. Aussitôt, un certain nombre de statues royales de Paris et d'autres villes sont abattues et détruites. Le 14 août, un autre décret clarifie les conditions de cette politique d'attentats légaux mais les encadre, les limite et définit une politique de conservation des monuments de la monarchie ${ }^{96}$. Les gestes commis dans la nécropole de Saint-Denis, présentés comme l'apogée de la sauvagerie de l'an II, témoignent de cette dimension attentatoire. Celle-ci commence avant la Terreur : le $1^{\mathrm{er}}$ août 1792 , la Convention décrète la destruction des tombeaux et des effigies. Un an plus tard, le 10 août 1793, des tombereaux chargés des attributs de la royauté sont brûlés sur la place de la Révolution. Mais cet iconoclasme très ciblé est jugé insuffisant. Du 12 au 25 octobre 1793, les corps royaux sont exhumés puis exposés. La mise à nu des cadavres, le prélèvement des cheveux et de poils de barbe sont des rituels profanatoires qui visent à 
salir les corps sacrés, à horrifier les contre-révolutionnaires, mais aussi à éradiquer symboliquement une monarchie fondée sur la continuité du pouvoir dynastique ${ }^{97}$. Toutefois, dans un contexte de guerres extérieure et civile, l'état échoue souvent à canaliser la violence qui s'exerce contre les emblèmes publics de la monarchie, de l'Église et de la féodalité. Cette violence n'est pas aveugle ${ }^{98}$. Elle cible les emblèmes les plus visibles dans l'espace public : les madones des coins des rues, les statues de saints ornant les façades des nombreux établissements religieux, mais aussi les croix et calvaires qui quadrillent l'espace rural. Les livres religieux sont en général épargnés. Les autodafés et destructions ne sont donc pas commis comme des actes d'irréligion ni des offenses à Dieu, mais comme des avertissements politiques destinés à frapper les esprits ${ }^{99}$. Enfin, si quelques représentants en mission se signalent par leur zèle destructeur (le fameux Albitte fait systématiquement raser les clochers dans les Alpes), leurs initiatives sont minoritaires et souvent désapprouvées par la Convention ${ }^{100}$.

Les attentats commis pendant la Révolution ne sont pas seulement matériels. En raison de leur caractère emblématique, de nombreuses personnes font l'objet d'attaques qui visent à les déshonorer, à les blesser ou à les éliminer, afin de semer la panique.

\section{Outrages et assassinats}

Sous la Révolution, les outrages politiques se multiplient. Les fessées publiques font partie de ces gestes, surtout lorsqu'elles frappent des femmes nobles, dont le statut social, reposant en partie sur la réputation morale, se voit littéralement violé par un rituel de salissure et de déshonneur: Théroigne de Méricourt perdra la raison d'avoir été ainsi fouettée devant la Convention par des militantes sans-culottes. L'humiliation publique de la flagellation, autrefois considérée comme une profanation ou un blasphème, se sécularise et se politise. La fessée prend valeur d'avertissement : le peuple peut se saisir du droit de punir les nobles ou les clercs (l'abbé Maury devient une cible récurrente des "fessées patriotiques») en les flétrissant publiquement, que la fessée soit réellement donnée ou représentée sur les estampes ${ }^{101}$. Dans le langage populaire, "fesser " ou « donner la pelle au cul » devient d'ailleurs synonyme d'expulser la noblesse tout entière : en débordant sa cible, la fessée révèle sa dimension attentatoire ${ }^{102}$. La tonte des cheveux, appliquée par les révolutionnaires ou les contre-révolutionnaires, vise régulièrement les femmes comme les hommes: inspirée par les rituels de la justice monarchique, cette marque d'infamie porte atteinte à la dignité et à l'honneur des individus dans l'espace public. Nouveaux représentants de la nation, les députés, mais aussi les gardes nationaux en faction, sont particulièrement visés par les moqueries et insultes, qui sont de plus en plus réprimées comme outrages à agents de l'État et dépositaires de l'autorité publique : un simple mauvais regard suffit parfois à se faire arrêter ${ }^{103}$.

Plus grave que l'outrage, l'assassinat désigne au $\mathrm{XVIII}^{\mathrm{e}}$ siècle un meurtre, une tentative de meurtre ou une importante atteinte à la personne. Même s'il se limite le plus souvent à l'échelle individuelle, le terme est aussi employé pour désigner l'élimination illégale et violente des détenteurs de l'autorité politique : «il se dit par extension, \& sur-tout en termes de Palais, D'un outrage fait de dessein formé, d'une trahison noire $»^{104}$. Lorsqu'il désigne un acte de violence commis à l'encontre d'un individu, l'assassinat ne désigne pas n'importe quel meurtre, mais un acte particulièrement ignoble, ne répondant pas aux règles communes de l'honneur : c'est un « [m]eurtre en trahison, \& de guet apens $»^{105}$. 

commis au cœur de l'espace public et lors des journées révolutionnaires, certains types de meurtres politiques dépassent la seule volonté d'éliminer les individus, mais visent à intimider le pouvoir et les ennemis du peuple. Les pendaisons aux lanternes en sont un exemple. Depuis la fin des années 1660 , les lanternes sont associées au pouvoir royal et au maintien de l'ordre policier dans les villes. Sévèrement punie, leur dégradation est perçue comme un acte d'insoumission ${ }^{106}$. Les transformer en potences relève donc à la fois d'une intimidation (le pendu est visible de tous), mais aussi d'un défi public à l'autorité ${ }^{107}$. Ainsi, Bertier de Sauvigny (22 juillet 1789) est pendu juste au-dessus d'un buste de Louis XIV, en pleine place de Grève, lieu des exécutions publiques organisées par la monarchie. La lanterne devient alors une métaphore de la contestation populaire de la légitimité de la justice monarchique : après le 10 août 1792, l'image des têtes royales suspendues à des lanternes, publiées chez Villeneuve, concrétise le transfert du droit de juger et de punir, $\mathrm{du}$ roi à la nation, en retournant contre le monarque ses propres moyens de répression. Avant l'an II, le peuple utilise donc les attentats pour retourner la terreur pratiquée depuis longtemps par l'État monarchique, contre ses représentants. (1795), procèdent du même mécanisme. Parfois poudrées, coiffées, rituellement exposée, ces têtes, ainsi transformées en étendards, visent des emblèmes politiques ou sociaux. En juillet 1789, Launay, Bertier de Sauvigny et Foulon de Doué étaient depuis longtemps des boucs émissaires, le premier pour sa charge de gouverneur de la Bastille, le second pour avoir sévèrement réprimé la Guerre des Farines en 1775, le troisième, ancien conseiller d'État, en raison de son intransigeance lors de la crise financière des années 1780. Comme l'affirme Thomas Paine contre Edmund Burke dès 1791, ces pratiques sont donc très ciblées. Prenant leur sens de leur publicité, elles visent à punir, mais aussi à terroriser. Surtout, elles s'inscrivent dans le droit fil des pratiques judiciaires des monarchies européennes, qu'elles retournent contre les responsables supposés des injustices ${ }^{108}$. La déambulation de ces têtes, portées par le peuple comme trophées, marque durablement les esprits et fait naître des pratiques politiques: les défilés (processions? manifestations?) contribuent à structurer les groupes politiques, à distinguer des meneurs (dont le fameux Jourdan, auteur autoproclamé des décapitations du 6 octobre 1789, bientôt surnommé « coupe-têtes »), mais aussi à montrer les visages des ennemis à abattre.

Catalysant toutes les peurs, inspirant les rumeurs de complot et de conspiration, le rôle des assassinats politiques dans l'actualité devient rapidement disproportionné par rapport à leur fréquence effective. En pleine transition démocratique, l'assassinat devient l'attentat par excellence, révélant à la fois la force et la vulnérabilité du nouveau régime. Sous la monarchie absolue, malgré le recours à la succession dynastique pour assurer la continuité du pouvoir, la mort violente du roi menaçait toujours l'équilibre du royaume tout entier. À partir de 1789, la cohésion du régime ne dépend plus du sort d'un corps unique qui, auparavant, monopolisait l'incarnation du pouvoir. Le nombre des cibles politiques augmente au rythme de la multiplication des nouveaux corps représentatifs de la nation, tous porteurs d'une parcelle de souveraineté. L'importance des attentats progresse proportionnellement à la démocratisation politique, en partie fondée sur la représentation. Le nouveau régime s'en trouve provisoirement fragilisé : potentiellement, tous ceux qui sont vus comme les emblèmes du peuple et dont les contre-révolutionnaires contestent la légitimité, sont désormais susceptibles d'être visés. Le partage corporel de la 
souveraineté augmente donc la probabilité des assassinats politiques et la vulnérabilité du régime: le nombre des victimes potentielles devient illimité. Cet abîme consacre l'attentat comme paradigme de la terreur politique ${ }^{109}$. Toutefois, l'élimination d'un individu ne peut plus à elle seule déstabiliser le pouvoir. La dilution de la souveraineté dans de multiples corps réduit d'autant la force de l'atteinte. Ensuite, la nation offre un réservoir bien plus inépuisable que la lignée dynastique pour assurer la continuité du pouvoir. Semant la peur, responsables des rumeurs et de l'obsession du complot, les assassinats politiques fragilisent donc le régime, mais peuvent aussi renforcer celui-ci. La Révolution et plus précisément l'éternité de la République, se fonde sur le sang des victimes des attentats politiques : un député est mort, vive la République ${ }^{110}$. Puisqu'audelà des personnes, les assassinats visent la nation tout entière, faire l'objet d'une attaque devient une marque suprême d'honneur. Un bon révolutionnaire est un homme mort ou menacé de mort. Pour devenir un héros, il faut d'abord être un martyr : Robespierre (août 1792), Marat (printemps 1793), François Chabot (juillet 1793), Billaud-Varenne ou SaintJust (juillet 1794), cherchent tous à utiliser les menaces dont ils assurent avoir fait l'objet pour construire leur carrière politique. Certains usurpateurs comprennent rapidement le profit qu'ils peuvent tirer de cette nouvelle échelle des honneurs. En décembre 1789, le garde national Trudon, en faction dans le Marais, se blesse lui-même avec un poinçon dans lequel se trouve enfilé un papier menaçant La Fayette de mort. Aussitôt qualifiée d'attentat, l'attaque simulée fait grand bruit. Démasqué, Trudon finit par se donner quatre coups de couteau en prison ${ }^{111}$. Qu'importe : l'affaire révèle le rôle central de la peur des attentats dans l'actualité politique.

Commencé avant 1789 , le processus d'empathie vis-à-vis des victimes de la violence monarchiste et de suspicion généralisée accompagne les premières journées révolutionnaires: quatre jours après la prise de la Bastille, Cormeron, tambour des gardes-françaises, s'effondre, croyant avoir été empoisonné. La rumeur prend de l'importance. Il faut le certificat d'examen pratiqué par le chirurgien de l'Hôtel-Dieu pour prouver que le mal de ventre provient d'une simple indigestion ${ }^{112}$. Avant cette date, les blessures, la maladie ou la mort d'un émeutier n'aurait probablement jamais occupé tant de place dans l'espace public: c'est parce que les vainqueurs de la Bastille et plus largement les patriotes, sont désormais considérés comme des corps emblématiques de la nation que leur sort préoccupe l'opinion, qui se sent touchée par leurs souffrances. La société révolutionnaire s'invente comme société compassionnelle, composée d'« hommes sensibles $»^{113}$. Les victimes sont placées au centre de la sollicitude républicaine. La peur des attentats devient le syndrome révolutionnaire par excellence.

La maladie ou la mort de tous ceux qui exercent une fonction civique est de ce fait aussitôt suspecte. Ce n'est pas complètement nouveau: au xvII ${ }^{\mathrm{e}}$ siècle, l'importance croissante du statut politique et social des membres de l'État, de plus en plus considérés comme les serviteurs de la chose publique, avait déjà entraîné une criminalisation accrue des assassinats « de guet à pens » commis à leur encontre. Perpétrés à l'aide de nouvelles armes (arquebuses, armes à feu), ces actes étaient de surcroît critiqués pour rompre le code de l'honneur venu de la culture du fer, fondé sur l'affrontement frontal de deux adversaires égaux ${ }^{114}$. Après 1789 , ce processus s'élargit. En décembre 1789, comme on l'a vu, l'Assemblée s'émeut au sujet de la fausse agression du garde national Trudon. À la même époque, les rumeurs sur le probable assassinat de La Fayette se multiplient. En septembre 1790, on assure que le journaliste Loustalot s'est écroulé en apprenant la nouvelle du massacre des Suisses de Châteauvieux. Sa défaillance est interprétée comme 
un assassinat. En réalité, le fameux rédacteur des Révolutions de Paris, vu comme porteparole du peuple, est probablement mort de maladie. En avril 1791, la mort naturelle de Mirabeau est également mise en doute et provoque une crise sans précédent ${ }^{115}$. Simultanément, les rumeurs d'attentats contre la famille royale se multiplient. Cette obsession se généralise après le 20 juin 1792 : alors qu'en juillet 1792, des commis accusent Pétion de fomenter l'assassinat de Louis XVI, en retour, celui-ci est soupçonné de vouloir s'appuyer sur les armées émigrées et sur les contre-révolutionnaires pour assassiner le peuple et ses représentants, objectif que le manifeste de Brunswick (août 1792), menaçant de mettre Paris à feu et à sang, semble attester ${ }^{116}$. En janvier 1793, le procès du roi peut être interprété comme un attentat légal ${ }^{117}$. La disparition du corps royal, dissous dans la chaux vive, accélère le processus de transfert de souveraineté, encore renforcé par l'assassinat déguisé du fils de Louis XVI, mort au Temple en juin 1795.

Depuis 1789 , les députés sont en effet déclarés inviolables. Leur porter atteinte est passible d'un nouveau crime : la lèse-nation. Le 22 mai 1792, le juge de paix La Rivière, qui tente de faire arrêter les députés ayant dénoncé le comité autrichien, est écroué et traduit devant la Haute Cour nationale de crime contre la Constitution et d'attentat contre la liberté individuelle des membres du Corps Législatif ${ }^{118}$. Les outrages commis publiquement contre les représentants du peuple sont criminalisés. À la fin du mois de mai 1792, les insultes que lancent les gardes du roi, qui viennent de se faire congédier, contre l'Assemblée nationale et les patriotes, sont perçues comme des attentats contre la nation : deux mois plus tard, leur commandant en chef Cossé-Brissac est accusé d'avoir " attenté à la Constitution et à la sûreté de l'État » en laissant cet événement se produire 119. Plus largement, ceux qui sont accusés d'avoir insulté, menacé ou attaqué des députés dans l'exercice de leur fonction sont déférés devant le tribunal criminel révolutionnaire pour «outrage à la représentation nationale $»^{120}$. À partir de l'automne 1792, l'essor constant de la peur des atteintes à la nation justifie la criminalisation des discours calomnieux, de l'insulte aux autorités au dénigrement des représentants du peuple ou des valeurs républicaines ${ }^{121}$. Le $1^{\text {er }}$ germinal III (21 mars 1795), la loi de Grande Police criminalise non seulement les attentats, mais aussi les injures contre les représentants. L'importance juridique croissante des députés et leur pouvoir d'identification transforment ceux-ci en enjeux politiques de premier ordre : leur porter publiquement atteinte devient une pratique d'opposition politique majeure, susceptible de semer la peur et de provoquer une crise de régime. C'est parce qu'il espère intimider les régicides que Pâris attaque Le Peletier de Saint-Fargeau la veille de l'exécution du roi. C'est parce qu'elle espère terroriser les Montagnards et inverser le rapport de force au profit des Girondins que Charlotte Corday tue Marat, le 13 juillet 1793. C'est parce qu'ils comptent stopper la Terreur en éliminant ses emblèmes que Cécile Renault et Ladmirat tentent d'assassiner Robespierre et Collot d'Herbois les 22 et 23 mai 1794. Le partage corporel de la souveraineté nationale n'est pas encore bien intégré dans la nouvelle culture républicaine, ce qui fragilise la stabilité du régime. Même si institutionnellement, le pouvoir n'est plus monopolisé par un seul individu depuis septembre 1792, les représentations de l'Ancien Régime perdurent: dans l'opinion publique, quelques individus, investis d'une aura particulière, concentrent à eux seuls les attentes, les espérances et parfois les haines politiques. Marat (en 1793) puis Robespierre (en 1794, que les opposants montagnards projettent d'assassiner en pleine Convention ${ }^{122}$ ) ont un peu remplacé le roi dans l'imaginaire politique national, mais dans le cadre d'une nouvelle sacralité républicaine. Les innombrables rumeurs et spéculations qui circulent sur leur maladie, leur faiblesse et leur mort, mille fois annoncée ou prophétisée, mais aussi les 
réels projets d'attentats qui les visent, révèlent les mutations de la culture politique. Dans les années 1750-1770, l'opposition politique, muselée, s'exprimait en partie à travers le fantasme collectif de la mort du roi ${ }^{123}$. Pendant la période révolutionnaire, la crainte des assassinats se reporte sur les simples porte-paroles de la nation, puis, à partir de l'an II, sur les corps les plus emblématiques de la nouvelle hiérarchie républicaine, comme les députés, les généraux et les ambassadeurs. Dès le 13 janvier 1793, Basseville est assassiné à Rome ; le 28 avril 1799, c'est au tour de deux des ministres plénipotentiaires français au congrès de Rastadt. Le 1er prairial an III, de jeunes tambours du faubourg Saint-Marcel se vantent d'avoir participé à l'assassinat de Féraud. Même s'ils ont simplement trempé leur sabre dans le sang du député, ils sont considérés comme coupables d'un attentat contre un représentant du peuple. Cet épisode mentionné par Haim Burstin montre à quel point l'attentat est devenu un mode d'action politique sensible au cours de la Révolution ${ }^{124}$. Commettre une violence spectaculaire et publique contre un représentant du peuple fait non seulement partie des marques de l'héroïsme politique contre-révolutionnaire, mais le geste est également devenu un instrument de promotion sociale dont il est possible de se vanter pour acquérir une certaine popularité. Comme ce que Burstin appelle le " protagonisme ", l'« attentat ", encourageant la surenchère, reposant sur l'illusion que les individus ou actes isolés peuvent faire basculer l'ordre des choses, joue un rôle dans la radicalisation des processus révolutionnaire et contre-révolutionnaire ${ }^{125}$. Formidables accélérateurs de carrières, les attentats font advenir leurs auteurs, la plupart du temps anonymes, au rang d'individus historiques et de figures légendaires, d'ailleurs souvent sans rapport avec la réussite ni la qualité morale de leur acte : totalement inconnue avant le 13 juillet, Marie Anne Charlotte de Corday d'Armont devient, en quelques jours seulement une des actrices les plus populaires de la Révolution française et rejoint ensuite, sous le nom de "Charlotte Corday", le club fermé des héros de l'histoire nationale ${ }^{126}$. Fondés sur la croyance que désormais, les hommes, même isolés, peuvent changer l'histoire du monde, les attentats commis contre les personnes ne révèlent pas seulement un processus d'individuation de l'action historique. Ils changent également la temporalité de la révolution : se caractérisant généralement par une disjonction entre les moyens employés (les petits couteaux de Corday et de Renault, le coup de fusil raté de Ladmirat, l'agression ratée contre Léonard Bourdon) et les effets obtenus, ces actes sont surmédiatisés et inspirent des réactions disproportionnées, en général inverses à celles escomptées par leurs auteurs. Commis par des individus marginalisés, déclassés ou en échec, mais néanmoins socialement intégrés, ou par des groupes politiques minoritaires, ces attentats sont en effet utilisés par les autorités pour augmenter la répression politique et diminuer les libertés publiques: en septembre 1793, le souvenir encore brûlant du violent assassinat de Marat légitime les demandes de mise à l'ordre du jour de la Terreur. Parce qu'ils choquent l'opinion, ces assassinats peuvent inspirer des instrumentalisations plus complexes : en juin-juillet 1794, les opposants de Robespierre réussissent à convaincre que la récente tentative d'assassinat perpétrée contre l'Incorruptible révèle la trop grande place que celui-ci a prise dans la République, comparable à celle du roi dans la monarchie, et justifie son arrestation ${ }^{127}$.

Plus globalement, la multiplication des attentats et le sentiment d'insécurité publique légitiment la mise en place de la "Terreur ", qu'il faut comprendre, à la suite de Sophie Wahnich, comme l'usage ciblé d'une violence légale, en réponse à la demande populaire de justice ${ }^{128}$. Les travaux fondateurs de Richard Cobb ont montré qu'à la fin du XVIII siècle, l'autorité politique est « en mesure, au fil des années, d'opposer à la force une force encore plus considérable, à la violence spontanée une violence rapide et efficace en 
même temps que discrète ${ }^{129}$ ». S'il existe une "politique de la Terreur », elle s'apparente avant tout à une politique antiterroriste, fondée sur l'instrumentalisation de la peur, la violence légale, préventive et dissuasive, ainsi que la restriction des libertés individuelles ${ }^{130}$. Après thermidor an II, en 1799, l'attentat commis lors du congrès de Rastadt contre les trois ministres plénipotentiaires représentant la France provoque un discours xénophobe qui légitime la guerre, présentée comme une lutte de la civilisation contre la barbarie. Utilisé par les autorités pour mobiliser les Français contre l'Autriche, l'attentat de Rastadt marque une rupture dans la brutalisation de la guerre et dans la conception de la Grande Nation: l'idéal de fraternisation se transforme en guerre de conquête, légitimée par la lutte contre le mal ${ }^{131}$.

Politiquement instrumentalisés et récupérés, les attentats font néanmoins basculer la Révolution dans un régime de l'imprévisibilité, qui révèle la difficile maitrise politique de l'opinion. Souvent, leurs effets échappent autant à ceux qui les commettent qu'à ceux qui tentent de les utiliser politiquement. En 1793, Charlotte Corday veut arrêter la Terreur mais ne fait que l'accélérer. Le 26 mai 1794 (7 prairial an II), le récit des attentats manqués contre Collot d'Herbois et Robespierre incite les députés à décider, contre toute réalité, tant la loi est inapplicable, qu'il ne sera plus fait de prisonniers britanniques ni hanovriens. En 1799, le Directoire tente d'exploiter l'indignation de l'opinion après l'attentat de Rastadt mais, silencieux devant les demandes de vengeance contre les royalistes, il est accusé de laxisme et échoue à contrôler la peur, ce qui favorise l'attente d'un homme fort : le coup d'État du 18 brumaire an VIII (9 novembre 1799), survenu huit mois après l'attentat, profite de ce contexte ${ }^{132}$. Un an plus tard, l'attentat de Saint-Nicaise n'affaiblit pas mais renforce le pouvoir du Premier Consul, qui peut se présenter comme un héros indestructible et mieux justifier la répression de ses opposants politiques ${ }^{133}$. L'opinion publique est une arme difficile à manier : parce qu'ils se traduisent par la peur et provoquent une demande de sécurité, les attentats contribuent généralement à consolider le régime en place.

\section{Conclusion}

48 À la fin du XVIII siècle, le recul des pratiques subversives socialement ritualisées comme la fête, le charivari et le carnaval, conjugué à l'élargissement de l'opinion publique et à la diffusion de nouveaux moyens techniques, favorisent le développement de nouvelles formes d'expression de la différence, de l'opposition et de la résistance politiques : avec la pétition, la campagne de presse, la manifestation, le boycott ou même la prise d'otage, l'attentat rejoint la gamme des outils utilisés par les minorités qui convertissent leur faiblesse en avantage et utilisent l'opinion publique comme levier d'expression et de mobilisation. Alors que l'on fait souvent naître le «terrorisme » en Russie à la fin des années 1870, il est possible de trouver à la fin du XVIII ${ }^{\mathrm{e}}$ siècle les traces d'une mutation de l'action politique, dont les acteurs du $\mathrm{xIX}^{\mathrm{e}}$ siècle seront les héritiers ${ }^{134}$.

Parmi les nouvelles pratiques d'opposition violente, l'attentat, proche des techniques de la guerre non réglée qui se développent exactement à la même période, se distingue par son but: tirer parti de la dissymétrie des forces pour intimider et provoquer la peur. Inséparable de l'obsession du complot et de la conspiration qui marque les processus rapides de démocratisation, surtout lorsque ceux-ci interviennent dans des contextes de guerres et de révolutions, le recours à l'attentat politique entraîne à son tour une transformation des politiques de maintien de l'ordre et de répression: de plus en plus 
fondée sur la mesure, la prévision et le modelage de l'« opinion publique », la politique devient, à partir de la fin du XVIII ${ }^{e}$ siècle, l'art de gouverner les émotions et, en premier lieu, la peur.

\section{NOTES}

1. Jacques SÉmelin, Purifier et détruire, Usages politiques des massacres et des génocides, Paris, Seuil, 2005 ; David EL KENZ, Le massacre, objet d'histoire, Paris, Gallimard, 2005.

2. Jean-Clément MARTIN, Violence et Révolution. Essai sur la naissance d'un mythe national, Paris, Seuil, 2006 ; Pierre SERNA, «Les massacres au temps des Révolutions », La Révolution française [En ligne], Editoriaux, mis en ligne le 14 janvier 2011, Consulté le 13 mai 2011. URL : http://lrf.revues.org/ index250.html.

3. Jean-Clément MARTIN, Violence et Révolution, op. cit., introduction.

4. Claudia Verhoeven, The odd man Karakazov: imperial Russia, modernity and the birth of Terrorism, Ithaca, Cornell University Press, 2009, introduction.

5. Pierre RÉTAT (dir.), L'attentat de Damiens. Discours sur l'événement au XVIII siècle, Paris, CNRS, 1979.

6. Michel CASSAn, La Grande Peur de 1610. Les Français et l'assassinat d'Henri IV, Seyssel, Champ Vallon, 2010.

7. Monique cotTret, Tuer le tyran? Le tyrannicide dans l'Europe moderne, Paris, Fayard, 2009, p. 308.

8. Sarah MAZA, Vies privées, affaires publiques : les causes célèbres de la France prérévolutionnaire, Paris, Librairie Fayard, 1997.

9. Des délits et des peines (1764), Paris, ENS éditions, 2009, p. 167.

10. Robert DARNTON, Bohème littéraire et Révolution: le monde des livres au XVIII siècle, Paris, Gallimard, 1982 ; Annie DUPRAT, Les rois de papier : la caricature de Henri III à Louis XVI, Paris, Belin, 2002.

11. Robert DARNTON, Le Diable dans un bénitier. L'art de la calomnie en France, 1650-1800, Paris, Gallimard, 2010 ; Steven L. KAPLAN, Le complot de famine : histoire d'une rumeur au XVIII siècle, Paris, Armand Colin, 1982.

12. Arlette FARGE, Dire et mal dire. L'opinion publique au XVIII siècle, Paris, Seuil, 1992.

13. Jean NICOLAS, La rébellion française. Mouvements populaires et conscience sociale (1661-1789), Paris, Le Seuil, 2002 ; Ian GILMOUR, Riots, Risings and Revolutions: Governance and Violence in Eighteenthcentury England, Londres, Pimlico, 1992.

14. Arlette FARGE, Jacques REVEL, Logiques de la Foule. L'affaire des enlèvements d'enfants, Paris 1750, Paris, Hachette, 1988, p. 65 ; Peter SHAw, American Patriots and the Rituals of Revolution, 1981; François JARRIGE, Au temps des «tueuses de bras ». Les bris de machines à l'aube de la société industrielle, Rennes, PUR, 2009.

15. Violence et contestation au Moyen Age, actes du 114e Congrès national des sociétés savantes, Paris, 1989, Section d'histoire médiévale et de philologie (Paris : Comité des travaux historiques et scientifiques, 1990 ; Christian Jounaud, Mazarinades: la fronde des mots, Paris, Aubier, 1985 ; Denis CROUZET, Les guerriers de Dieu: la violence au temps de troubles de religion, vers 1525-1610, Seyssel, Champ Vallon, 2005. 
16. Yves-Marie BERCÉ, Fête et révolte : essai d'histoire des mentalités populaires du XVIII siècle, Paris, Hachette, 1976.

17. Mona ozouf, La fête révolutionnaire, 1789-1799, Paris, Gallimard, 1976 ; Alain CORBIN, Le village des cannibales, Paris, Aubier, 1990 ; Peter SHAW, American Patriots and the Rituals of Revolution, op cit.

18. Alain CABANTOUS, Histoire du blasphème en Occident : fin XVI ${ }^{e}-$ milieu XIX ${ }^{e}$ siècle, Paris, Albin Michel, 1998.

19. Jean NICOLAS, La rébellion française. 1661-1789, Paris, Gallimard, Folio, 2008 [1 ${ }^{\text {re }}$ éd. 2002], p. 470 ; STENDHAL, Vie de Henry Brulard, Paris, Glénat, 1988, chapitre V.

20. Philippe BOURDIN, Jean-Luc CHAPPEY (dir.), Révoltes et révolutions en Europe et aux Amériques (1773-1802), Paris, Sedes, 2004, p. 59-61; Micah AlPAUGH, "The Politics of Escalation in French Revolutionary Protest: Political Demonstrations, Non-Violence and Violence in the grandes journées of 1789 », French History, Volume 23 Number 3 September 2009, p. 336-360.

21. Lise ANDRIES, Cartouche, Mandrin et autres brigands du XVIII siècle, Paris, Desjonquères, 2010 ; Monique COTTRET, La Bastille à prendre. Histoire et mythe de la forteresse royale, Paris, PUF, 1986.

22. Jean NICOLAS (dir.), op. cit., p. 389 et suiv.

23. Keith Michael BAKER, Au tribunal de l'opinion. Essai sur l'imaginaire politique au XVIII siècle, Paris, Payot, 1993.

24. Pierre KARILA-COHEN, L'Etat des esprits: l'invention de l'enquête politique en France, 1814-1848, Rennes, PUR, 2008.

25. Micah ALPAUGH, art. cit.

26. Jean-Paul MARAT, Plan de législation criminelle, Paris, 1790.

27. Moniteur Universel, 25 octobre 1790.

28. Projet de l'organisation du pouvoir judiciaire, proposé à l'Assemblée nationale par le Comité de Constitution, Paris, Baudoin, s. d., p. 3-4.

29. Anne simonin, Le déshonneur dans la République. Une histoire de l'indignité nationale, 1791-1958, Paris, Grasset, 2008, p. 233-236 ; Patrice GUENIFfEY, La politique de la Terreur. Essai sur la violence révolutionnaire, 1789-1794, Paris, Fayard, 2000, p. 93-98.

30. Isabelle SOMMIER, Le Terrorisme, Paris, Flammarion, 2000 ; Claudia VERHOEVEN, The odd man Karakazov, op. cit.

31. Karine SALOMÉ, L'Ouragan homicide, Les attentats politiques en France au XIX ${ }^{e}$ siècle, Seyssel, Champ Vallon, 2011.

32. Henry LAURENS, "Le terrorisme comme personnage historique », dans Henry LAURENS, Mireille DELMAS-MARTY, Terrorismes. Histoire et droit, Paris, CNRS éditions, 2010, p. 9-88, p. 18.

33. Moniteur Universel, 25 juillet 1789.

34. Anonyme, Complot infernal exécuté à Quincey, affreux désordres en Franche-Comté et en Bourgogne, Paris, chez Gueffier jeune, 1789.

35. Georges LefebVRe, La Grande Peur de 89, Paris, Armand Colin (1934), 1970.

36. ANONYME, Complot infernal exécuté à Quincey, op. cit., p. 4.

37. Georges LEFEBVRE, op. cit., p. 72.

38. AN/D/XXXIX $1, \mathrm{n}^{\circ} 1,8$ août 1789.

39. AN D XXXIX' $29, \mathrm{n}^{\circ} 292,23$ octobre 1789

40. Précis historique de l'attentat de Billon, horloger à Senlis, Senlis, NLF des Rocques, 1789.

41. Grand détail et relation de l'exécrable attentat commis par le dénommé Billon horloger ; arrivé à Senlis, le 13 décembre 1789, Senlis, NLF des Roques, 1789.

42. Karine SAlOMÉ, op. cit.; Daniel ARASSE, La Guillotine ou l'imaginaire de la Terreur, Paris, Flammarion, 1987, p. 49.

43. Moniteur Patriote, $\mathrm{n}^{\circ} \mathrm{XIX}$.

44. Détails de la fête nationale du 14 juillet 1790, p. 7 ; BN Mss. Nouv. Acq. Fr. 2665, fol. 279.

45. AP, Sections de Paris, procès-verbaux des commissaires de police (Arsenal), 4 septembre 1791. 
46. Le Mercure Universel, 18 décembre 1791.

47. Journal de l'Assemblée nationale, ou Journal logographique, séance du dimanche soir 25 décembre 1791.

48. Annales patriotiques et littéraires, $\mathrm{n}^{\circ} \mathrm{XXIX}, 29$ janvier 1790.

49. AN F $^{7} 4590,29$ juin 1792.

50. Thomas LE ROUX, Le laboratoire des pollutions industrielles. Paris, 1770-1830, Albin Michel, 2011.

51. Karine SALOMÉ, op. cit., p. 283.

52. Aurélien LIGNEREUX, «Le moment terroriste de la chouannerie : des atteintes à l'ordre public aux attentats contre le Premier Consul », voir l'article dans ce numéro.

53. Sur le sud de la France: Valérie sotтocASA, "Les protestations populaires et la nuit", communication présentée lors du colloque La Révolution française et la nuit, Clermont-Ferrand, 5 et 6 septembre 2011, à paraître aux Presses Universitaires Blaise-Pascal.

54. Gérard CHALIAND, Arnaud Blin (dir.), Histoire du terrorisme. De l'Antiquité à Al-Qaïda, Paris, Bayard, 2006.

55. Guillaume MAZEAU, «Usages de la pyrotechnie pendant la Révolution française", communication présentée colloque La Révolution française et la nuit, Clermont-Ferrand, 5 et 6 septembre 2011, à paraître aux Presses Universitaires Blaise-Pascal.

56. Versailles et Paris, ou rapport très exact des séances de l'Assemblée nationale et des Communes de Paris, $\mathrm{n}^{\circ}$ XIII, jeudi 13 août 1789.

57. Lettre de M. Gouvion, major général de la garde nationale, à Bailly, signalant la fabrication clandestine de poudre dans une maison du faubourg Saint-Antoine, 22 mai 1790, BN Mss. Fs. $1: 697$.

58. Annales Patriotiques et Littéraires, janvier 1784, p. 449.

59. Martine ACERRA, «Des rafles de Boscawen au "Vengeur du Peuple" ", La Révolution française [En ligne], Les massacres aux temps des Révolutions, mis en ligne le 08 janvier 2011, Consulté le 13 mai 2011. URL : http://lrf.revues.org/index193.html.

60. Guillaume MAZEAU, Le Bain de l'histoire. Charlotte Corday et l'attentat contre Marat (1793-2009), Seyssel, Champ Vallon, 2009.

61. Denise TURREL, Le Blanc de France. La construction des signes identitaires pendant les guerres de Religion (1562-1629), Genève, Droz, 2005.

62. Daniel ROCHE, La culture des apparences : une histoire du vêtement (XVII ${ }^{e}-\mathrm{XVIII}{ }^{e}$ siècles), Paris, Fayard, 1991.

63. Leora AUSLANDER, Des Révolutions culturelles. La politique du quotidien en Grande-Bretagne, en Amérique et en France, XVII ${ }^{e}$-XIX ${ }^{e}$ siècle, Toulouse, PUM, 2010.

64. Monroe fRIEDMAN, Consumer Boycotts: Effecting Change through the Marketplace and the Media, London Routledge, 1999. Olivier CHRISTIN, Une révolution symbolique: l'iconoclasme huguenot et la reconstruction catholique, Paris, Éditions de Minuit, 1991.

65. Emmanuel FUREIX, «L'iconoclasme: une pratique politique ? (1814-1848)», dans Laurent LE GALL, Michel OFFERLÉ, François PLOUX (dir.), La politique informelle en France et en Europe, XIX ${ }^{e}-\mathrm{XXI}{ }^{e}$ siècles, Rennes, PUR, 2011.

66. Emmanuel FUREIX, Ibidem.

67. Ibidem.

68. Jean-Clément MARTIN, Violence et Révolution, op. cit.; Michel Vovelle, Le Siècle des Lumières, p. 381.

69. Jacques GODECHOT, La prise de la Bastille. 14 juillet 1789 (1965), Paris, Gallimard, 1989, p. 295-296.

70. Révolutions de Paris, $\mathrm{n}^{\circ} 49$, du 12 au 19 juin 1790.

71. Jean-Claude CARON, Les feux de la discorde. Conflits et incendies dans la France du XIXe siècle, Paris, Hachette Littératures, 2006 ; Jean-Clément MARTIN, Ibidem, p. 54. 
72. François JARRIGE, Au temps des «tueuses de bras». Les bris de machine à l'aube de l'ère industrielle (1780-1860), Rennes, PUR, 2009.

73. Eric J. HOBSBAwn, «Les briseurs de machines", Revue d'histoire moderne et contemporaine, 2006/5, n 53-4 bis, p. 16; Edgar P. THOMPSON, «The moral economy of the English crowdin the eighteenth century ", Past \& Present, 50, 1971, p. 76-136.

74. AN/D IV/10, $n^{\circ} 99,25$ juin 1790.

75. Nicholas ROGERS, Crowds, Culture, and Politics in Great Britain, Oxford, Clarendon Press, 1998, p. 166.

76. Georges lefebvre, La Grande Peur de 89, op. cit.; Timothy tackett, «La Grande Peur et le complot aristocratique sous la Révolution française ", Annales historiques de la Révolution française [En ligne], 335 | janvier-mars 2004, mis en ligne le 20 février 2008, consulté le 23 mars 2011.

77. Jean-Claude CARON, op. cit.

78. Georges LefEBVRE, La Grande Peur de 89, op. cit., p. 140.

79. BROSSAIS DU PERRAY, Remarques historiques sur la Bastille, 1789 ; Abbé PROYART, CEuvres complètes, Paris, Méquignon fils aîné, 1819, p. 61 ; P. DAVID, La prise de la Bastille ou la liberté conquise : pièce nationale en quatre actes, 1790 , acte 2 scène I.

80. Monique COTTRET, Une Bastille à prendre, op. cit.

81. Hans-Jürgen LÜSEBRINK, Rolf REICHARDT, The Bastille: a history of a symbol of despotism and freedom , Duke University Press, 1997, chap. 2.

82. Piétinée ? Les historiens se divisent sur la nature des faits.

83. Haim BURSTIN, Une Révolution à l'œuvre: le faubourg Saint-Marcel (1789-1794), Seyssel, Champ Vallon, 2005, p. 625 ; Albert SовоUL, «Un épisode des luttes populaires en septembre 1793. La guerre des cocardes ", Annales historiques de la Révolution française, 1961, p. 52-55.

84. Annie GEFFROY, "A bas le bonnet rouge des femmes! (octobre-novembre 1793)", dans Les Femmes et la Révolution française, t. 2, Toulouse, PUM, 1990, p. 345-351.

85. En Belgique, la pratique est attestée dès l'été 1791 : Révolutions de Paris, du 23 au 30 juillet 1791.

86. Jean-Marc DEVOCELLE, "La cocarde directoriale. Dérives d'un symbole révolutionnaire ", Annales historiques de la Révolution française, 1992, n²89, p. 355-366.

87. Simon P. NEWMAN, Parades and the Politics of the Street. Festive Culture I the Early American Republic, Philadelphia, University of Pennsylvania Press, 1997, chap. 5.

88. Mona ozouf, « Du mai de la liberté à l'arbre de la liberté : symbolisme révolutionnaire et tradition paysanne ", Ethnologie française, 1975.

89. AN W 252, 16 septembre 1792 ; Michel vovelle, La Révolution contre l'Église. De la Raison à l'Être Suprême, Bruxelles, Complexe, 1988, p. 253.

90. Michel DUVAL, «Les arbres de la liberté en Bretagne sous la Révolution (1792-1799) », dans François LEBRUN, Roger DUPUY (dir.), Les résistances à la Révolution, Paris, Imago, 1987, p. 55-67.

91. François LACOMBE, Recueil de lois, arrêtés, proclamations, traités, notes ministérielles, et pièces diverses qui ont paru d'ès l'origine de la Révolution helvétique jusqu'à la fin de l'année 1798, Genève, 1799, vol. 1, p. 66.

92. AN C $39, \mathrm{n}^{\circ} 353$ bis.

93. Jean-René HÉBERT, Fureur du Père Duchesne contre les soixante Calotins qui ont saccagé et profané l'autel de la patrie, et assassiné la sentinelle du Champ-de-Mars, et désarmé le corps de garde, 1790.

94. Récit de l'attentat commis hier 6 décembre, contre l'autel de la Patrie, dans le champ de la Fédération, par des abbés, Paris, de l'imprimerie du Postillon, 1790.

95. Edouard POMMIER, L'art de la liberté. Doctrines et débats de la Révolution française, Paris, Gallimard, 1991, p. 100.

96. Ibidem, p. 102. 
97. Jean-Marie LE GALL, Le mythe de Saint-Denis entre Renaissance et Révolution, Seyssel, Champ Vallon, 2007.

98. Serge BIANCHI, «Le «vandalisme » anti-féodal et le « vandalisme » anti-religieux dans le sud de l'Ile-de-France de 1789 à l'an III », dans Simone BERNARD-GRIFFITHS, Marie-Claude CHEMIN, Jean EHRARDT (dir.), Révolution française et "vandalisme révolutionnaire ", Paris, Universitas, 1992, p. $157-167$.

99. Ibidem, p. 95.

100. Michel VOVELLE, La Révolution contre l'Eglise, op. cit., p. 81.

101. Annie DUPRAT, «La trésorière des Miramionnes n'avais qu'une fesse ", Annales historiques de la Révolution française, $\mathrm{n}^{\circ} 361$, juillet/septembre 2010, p. 53-64.

102. Michel BIARD, Dictionnaire du Père Duchesne, Paris, Tallandier, 2010.

103. AP, Section de Paris, procès-verbaux des commissaires de police (Muséum).

104. Dictionnaire de l'Académie française, $4^{\mathrm{e}}$ édition (1762).

105. Ibidem.

106. Catherine DENYS, "Le bris de lanterne dans les villes du nord de la France au XVIII ${ }^{\mathrm{e}}$ siècle ", dans Benoît GARNOT (dir.), La Petite Délinquance du Moyen Âge à l'époque contemporaine, Dijon, 1998, p. 309-319.

107. Alain CABANTOUS, Histoire de la nuit, XVII ${ }^{e}-X V I I I^{e}$ siècle, Paris, Fayard, 2009, p. 172-173.

108. Thomas PAINE, The Rights of Man: being an answer to M. Burke's attacks on French Revolution, Dublin, 1791, p. 17.

109. Frédéric NEYRAT, Le Terrorisme. Un concept piégé, Paris, ère, 2011, p. 102.

110. Joseph CLARKE, Commemorating the Dead in Revolutionary France. Revolution and Remembrance, 1789-1799, Cambridge: Cambridge University Press, 2007.

111. AN, D/XXIX $44, n^{\circ} 417,28$ décembre 1789.

112. AN, AA 41, $\mathrm{n}^{\circ} 13000$.

113. Sophie WAHNICH, Les émotions, la Révolution française et le présent, Paris, Editions du CNRS, 2009.

114. Michel NASSIET, La violence, une histoire sociale, France, XVI ${ }^{e}-X V I I I^{e}$ siècles, Seyssel, Champ Vallon, 2011, p. 121.

115. Camille Desmoulins parle des « assassins de Loustalot » dans Le Vieux Cordelier, $\mathrm{N}^{\circ} \mathrm{V}$, Quintidi Nivôse, 1ere décade, an II (fin dec 1793).

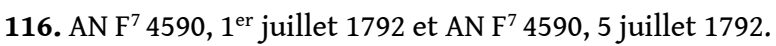

117. Michael WALZER, Regicide and Revolution: speeches at the trial of Louis XVI, Columbia University Press, 1992.

118. AN $F^{7} 3688^{1}$, 27 mai 1792 ; AN C150, nº 259, 2 juin 1792.

119. AN C150, n² 260, 12 juin 1792.

120. Le 9 juillet 1793, c'est le cas des membres de la municipalité de Pigneau (Var), accusés d'avoir agressé Fréron et Barras.

121. Charles walton, Policing Public Opinion in the French Revolution. The Culture of Calumny and the Problem of Free Speech, Oxford, Oxford University Press, 2009, p. 4.

122. Georges LEFEBVRE, Etudes sur la Révolution française, Paris, PUF, 1954, p. 79.

123. Arlette FARGE, Dire et mal dire. L'opinion publique au XVIII ${ }^{e}$ siècle, Paris, Seuil, 1992.

124. Haim BURSTIN, L'invention du sans-culotte, Regards sur le Paris révolutionnaire, Paris, Odile Jacob, 2005 , p. 217 et suiv.

125. Haim BURSTIN, « Le "protagonisme" comme facteur d'amplification de l'événement : le cas de la Révolution française ", dans L'Evénement, actes du colloque d'Aix-en-Provence (1983), PUA, 1986, p. 65-75.

126. Guillaume MAZEAU, Charlotte Corday. Généalogies d'un crime, Paris, Vendémiaire, à paraître en 2013. 
127. Jean-Clément MARTIN, Violence et Révolution, op. cit.

128. Sophie WAHNich, La liberté ou la mort, essai sur la Terreur et le terrorisme, Paris, La Fabrique éditions, 2003 ; voir aussi Guillaume MAZEAU, «La Terreur, laboratoire de la modernité », dans Jean-Luc CHAPPEY, Guillaume MAZEAU, Frédéric RÉGENT, Pierre SERNA, dans Pour quoi faire la Révolution, Paris, Agone, 2012.

129. Richard Совв, La protestation populaire en France (1789-1820), Paris, Calmann-Lévy, 1975, p. 182.

130. Patrice GUENIFfEY, La politique de la Terreur. Essai sur la violence révolutionnaire, Paris, Fayard, 2000.

131. Jean-Luc CHAPPEY, "L'assassinat de Rastadt et les enjeux du "cri de vengeance" sous le second Directoire ", dans Philippe BoURdin, Jean-Claude CARON, Mathias BERnARD (dir.), La Voix et le Geste. Une approche culturelle de la violence socio-politique, Clermont-Ferrand, Presses Universitaires Blaise Pascal, 2005, pp. 69-96.

132. Jean-Luc CHAPPEY, Ibidem.

133. Karine SALOMÉ, op. cit., p. 80.

134. Karine SALOMÉ, op. cit. Je remercie Alain Cabantous, Jean-Luc Chappey, Quentin Deluermoz, Jean-Clément Martin et Timothy Tackett pour leurs conseils avisés.

\section{RÉSUMÉS}

À la fin du XVIII ${ }^{\mathrm{e}}$ siècle, au gré des révoltes et révolutions, apparaissent de nouvelles formes de l'action politique : les attentats. Souvent perpétrés à l'aide d'armes plus destructrices, ces actes sont également au moins autant destinés à émouvoir l'opinion populaire qu'à salir, blesser ou éliminer des emblèmes politiques, que ceux-ci soient des objets ou des personnes. De la prise de la Bastille (14 juillet 1789) à l'attentat de la rue Saint-Nicaise (24 décembre 1800), en passant par l'explosion du château de Quincey (19 juillet 1789), l'assassinat de Marat (13 juillet 1793), les arrachages des arbres de la liberté, l'iconoclasme de l'an II et les têtes plantées au bout des piques, la transition démocratique qui touche la France entre 1789 à 1800 se caractérise par l'émergence de nouvelles manières d'exercer la violence, à la fois plus dévastatrices et plus symboliques qu'auparavant, et qui, pratiquées par les minorités comme par le pouvoir politique, lègueront $\mathrm{au} \mathrm{XIX}^{\mathrm{e}}$ siècle un répertoire de pratiques contribuant à la naissance du terrorisme contemporain.

The end of the $18^{\text {th }}$ century gives birth to new forms of political action: political attempts or attacks. More and more often committed with weapons of massive destruction, as bombs or explosive machines, these attacks not only try to injure or kill human targets, but also to spread fear in public opinion, in order to express minorities' claims, and to influence political debates and decisions by direct activism. This paper claims that revolutionary violence, which has been mainly studied through collective massacres, must be considered in its different aspects: political murders, iconoclasm, material destructions and symbolic rituals are part of a new phenomenon, linked to the French democratic transition, one century before the "official" birth of modern terrorism. 
INDEX

Mots-clés : assassinat, attentat, iconoclasme, massacres, Révolution française, violence Keywords : French Revolution, iconoclasm, massacres, political attacks, political murders, violence 